Working Paper in Economics No. 796

\title{
Are women less effective leaders than men? Evidence from experiments using coordination games
}

\section{Lea Heursen, Eva Ranehill and Roberto A. Weber}

Department of Economics, November 2020 


\title{
Are women less effective leaders than men? Evidence from experiments using coordination games
}

\author{
Lea Heursen $^{\mathrm{a}}$, Eva Ranehill ${ }^{\mathrm{b}}$ and Roberto A. Weber ${ }^{\mathrm{c}}$ \\ ${ }^{a}$ Department of Economics, Humboldt University Berlin \\ ${ }^{\mathrm{b}}$ Department of Economics, University of Gothenburg \\ ${ }^{\mathrm{c}}$ Department of Economics, University of Zurich
}

October 28, 2020*

\begin{abstract}
We study whether one reason behind female underrepresentation in leadership is that female leaders are less effective at coordinating action by followers. Two experiments using coordination games investigate whether female leaders are less successful than males in persuading followers to coordinate on efficient equilibria. Group performance hinges on higher-order beliefs about the leader's capacity to convince followers to pursue desired actions, making beliefs that women are less effective leaders potentially self-confirming. We find no evidence that such bias impacts actual leadership performance, identifying a preciselyestimated null effect. We show that this absence of an effect is surprising given experts’ priors.
\end{abstract}

Keywords: gender; coordination games; leadership; experiment

JEL codes: D23, C72, C92, J1

\footnotetext{
* We are greatly thankful to Amanda Chuan, Marina Gertsberg, Pavitra Govindan, Christina Rott and Silvia Saccardo who gave helpful comments on earlier drafts, as well as to participants at several conferences and seminars for helpful comments and suggestions. We thank the Swiss National Science Foundation (100010_149451) and the Jan Wallander and Tom Hedelius Foundation (Handelsbankens Forskningsstiftelser Grant P2010-0133:1) for generous financial support. We are also grateful to Philipp Grossman and Ernesto Reuben for sharing their data with us. Simon Grässli provided excellent research assistance.
} 


\section{Introduction}

Economic research has devoted considerable attention to the persisting underrepresentation of women in leadership positions. Studies have investigated the explanatory power of factors such as gender gaps in human capital acquisition, parental investment, discrimination and economic preferences and psychological traits (Bertrand and Hallock 2001; Gobillon et al. 2015; Blau and Kahn 2017; Goldin and Rouse 2000; Kleven et al. 2019; Buser et al. 2014; Preece and Stoddard 2015) In this study, we propose and test another explanatory factor-whether women may be placed in leadership roles at lower rates than men simply because they are less effective leaders.

An essential function of leadership is the ability to persuade groups of followers to pursue a common vision or course of action promoted by the leader (Kotter 2001; Dionne et al. 2004; Cooper et al., in press). Inter-personal and coordination skills are increasingly desired in leaders, as suggested by recent analysis of C-suite job descriptions (Fuller et al. 2020). In this paper, we investigate the simple question of whether the mere fact that a leader is male or female matters for the ability to coordinate followers' behavior on a desired course of action.

To address this question, we implement two laboratory experiments, each presenting a task that attempts to isolate leadership into the above functions of persuasiveness and ability to motivate, absent any other dimensions of real or perceived ability or competence. ${ }^{1}$ Both experiments use simple coordination games in which the leader's task is to persuade a group of followers to implement the leader's direction. The leader sends free-form statements to all followers in a group, before the followers individually and simultaneously select actions. Following the leader's direction is beneficial only to the extent that all other followers do so as well. Hence, in these settings, both followers' first-order beliefs about the value of the leader's directive and their higher-order beliefs over whether others will be persuaded matter for the leader's capacity to successfully motivate action by followers.

Our studies are designed to test two different mechanisms that may result in a gender gap in leader effectiveness. First, male and female leaders’ directives may differ objectively in terms of, for example, quality or persuasiveness. In our experiments, that would mean

\footnotetext{
${ }^{1}$ Two major advantages of the experimental setting are that we can randomly assign individuals to groups, and to the role of leader, and thus causally estimate the effectiveness of different types of leaders. Moreover, we can exogenously vary whether or not followers know the gender of the leader, holding all other aspects of the decision environment constant. This allows us to causally explore how gender stereotypes about effective leadership matter for leaders’ ability to impact group outcomes.
} 
that, ceteris paribus, male and female leaders make different types of statements, and that these differences influence the effectiveness of leaders' directives.

Second, even if male and female leaders are fundamentally equally capable of issuing persuasive directives, gendered perceptions may impact how persuasive directives are perceived to be from male versus female leaders. The perception that female leaders are less effective than men is widespread. For example, according to the last wave of the World Value Survey (2010-2014) 48.5\% of the respondents worldwide agree with the statement that men make better political leaders than women. ${ }^{2}$ Previous research in psychology and sociology indicates that attitudes towards female leaders are often more negative than those towards male leaders (Rudman and Kilianski 2000; Rudman and Glick 2001; Eagly and Karau 2002) and that women may be seen as less legitimate leaders and encounter more resistance to their authority (Ridgeway 2001). Relatedly, evidence indicates that characteristics associated with femininity are different from those typically associated with effective leadership (see, e.g., Koenig et al. 2011's meta review of 69 studies on gender leaders stereotypes) and that men exert, overall, greater influence than women due to gender stereotypes about higher male competence and agency (Carli 2017).

Thus, in our settings, women may be less effective leaders than men either because they are worse at persuading followers to pursue the leaders' directives, or because followers' relatively more pessimistic beliefs about female leaders' capacity to generate support become a self-fulfilling prophecy. We test these two mechanisms, separately, by varying the leader's gender and whether or not the leader's gender is known to followers.

We structured our research around the following hypotheses. The null hypothesis (H0) is that men and women are equally effective as leaders - i.e., that they achieve, on average, the same group outcomes in our two experiments. Against this null hypothesis, we test two alternative hypotheses, based on the above two different mechanisms underlying a potential gender difference. First, if women are actually worse at generating support from followers, we should observe them to be less effective leaders independently of whether followers observe their gender (H1a). Second, if actual leadership does not differ, but performance differences arise only due to self-confirming perceptions of leadership quality, then we expect to see a difference only when the leader's gender is known to followers (H1b).

\footnotetext{
2 The corresponding share of respondents indicating a preference for men as business executives is $43 \%$. Respondents could only agree or disagree with the statement. Hence, the question does not allow identifying the share of respondents who would agree with the reversed statement.
} 
Our first experiment uses a variant of the "turnaround game," first introduced by Brandts and Cooper (2006) and widely employed in recent research on leader effectiveness. The game involves a group of followers who play a repeated weak-link coordination game. In the weak-link game, each group member independently selects a level of investment to make in a group project. Investments exhibit complementarities- the return from the group project is based on the minimum amount invested by any group member and investments higher than the minimum yield no benefit. This feature leads most groups to coordinate on the least efficient equilibrium after a few rounds. At this stage, we introduce a leader who sends a written message to the group members prior to each period of the coordination game. Group leaders are incentivized to move the group to more efficient equilibria; that is, to use their directives to elicit increased investment from all followers. Previous literature indicates that statements made by leaders, as well as the leader's identity, matter in this environment and influence the extent to which groups coordinate on efficient equilibria (Brandts and Cooper 2007; Brandts et al. 2015; Bhalotra et al. 2018). Our primary measure of leader effectiveness is the average investment in the group once the leader is active.

In this environment, we find that male and female leaders are equally effective at coordinating followers and increasing investments. This result holds both when the gender of the leader is visible to followers and when it is not. While our sample of followers consists of students who may hold more progressive views on gender than the general population, we find that, on average, they hold stereotypical views on gender and leadership, as measured both using an implicit association test and more explicit attitudinal measures.

The lack of differences in male and female effectiveness in our study are consistent with other studies conducted concurrently with our Experiment 1, also employing the weaklink coordination game to evaluate the effectiveness of male and female leadership (Reuben and Timko 2018; Grossman et al. 2019). Like our Experiment 1, these studies do not find statistically significant evidence of a gender gap in leader performance. However, these earlier studies cannot rule out sizable gender effects in the hypothesized direction (see Figure 1). This is also true of our first experiment, despite the fact that we use a considerably larger sample. However, the fact that three research teams independently sought to test the same hypothesis that women are less effective than men in a leadership role involving coordination provides a first indication of the surprising nature of a null result.

The evidence from our first experiment and these other studies is based on team production involving a weak-link technology. While for many reasons this is a good setting in which to study leadership (Foss 2001; Weber et al. 2001; Brandts and Cooper 2007; 
Brandts et al. 2015), it may not be ideal for identifying a gender gap in leader persuasiveness. For starters, in this setting followers always gain by following a leaders' advice as long as other do so, implying that there is always a strong incentive to find a leader's directives persuasive, regardless of gender. Moreover, the structure of the game means that followers will want to pursue a leader's recommended action whenever they believe that the probability others will do so is above a threshold determined by the game's payoffs. Thus, the weak-link game will only detect a gap in persuasiveness between two leaders if the resulting expected follower response probabilities lie on opposite sides of this threshold. (We illustrate this point formally in Appendix B1.)

Based on these considerations, we design a second experiment to conduct a more precise test of the relative effectiveness of male and female leaders. In this experiment, two followers simultaneously decide which of two competing leaders to follow. Specifically, the pair of followers play a pure-matching coordination game in which they are incentivized to coordinate on one of two leaders' directives. Leaders are incentivized to persuade as many pairs of followers as possible to coordinate on their preferred action through a written statement shown to the followers when they attempt to coordinate. As in Experiment 1, we explore the impact of varying leader gender and its visibility. Hence, while Experiment 2 differs from Experiment 1 in various ways, both experiments are based on a coordination game and leverage second-order beliefs and gender stereotypes about leader effectiveness to explore the gender gap in leader effectiveness. However, since in Experiment 2 followers only care about picking the same leader, even very small differences in leaders' actual or perceived persuasiveness are likely to have big effects on which leader is followed. Our primary measure of leader effectiveness in this setting is the rate at which female and male leaders are followed whenever the competing leader is of opposite sex.

As we note above, we interpret the pursuit of a similar research question by different research teams as suggestive evidence of a prior belief of a leader gender effectiveness gap. To obtain a more concrete measure of such priors, before revealing the results of Experiment 2, we elicited predictions for the gender blind and the gender visible conditions from 54 participants at a workshop on gender economics. On average, these researchers expected a large difference when the gender of the leaders was visible (see Figure 1) but not otherwise. Surprisingly, however, and consistent with the null results of Experiment 1, this much more sensitive test yielded no indication of a gender gap in leader effectiveness. While the leaders' statements are attended to by followers and positively impact the rates of 
coordination, men and women are followed at nearly identical rates, independently of whether or not their gender is visible.

\section{Figure 1. Observed and Predicted Gender Gap in Leadership Effectiveness Across Different Studies}

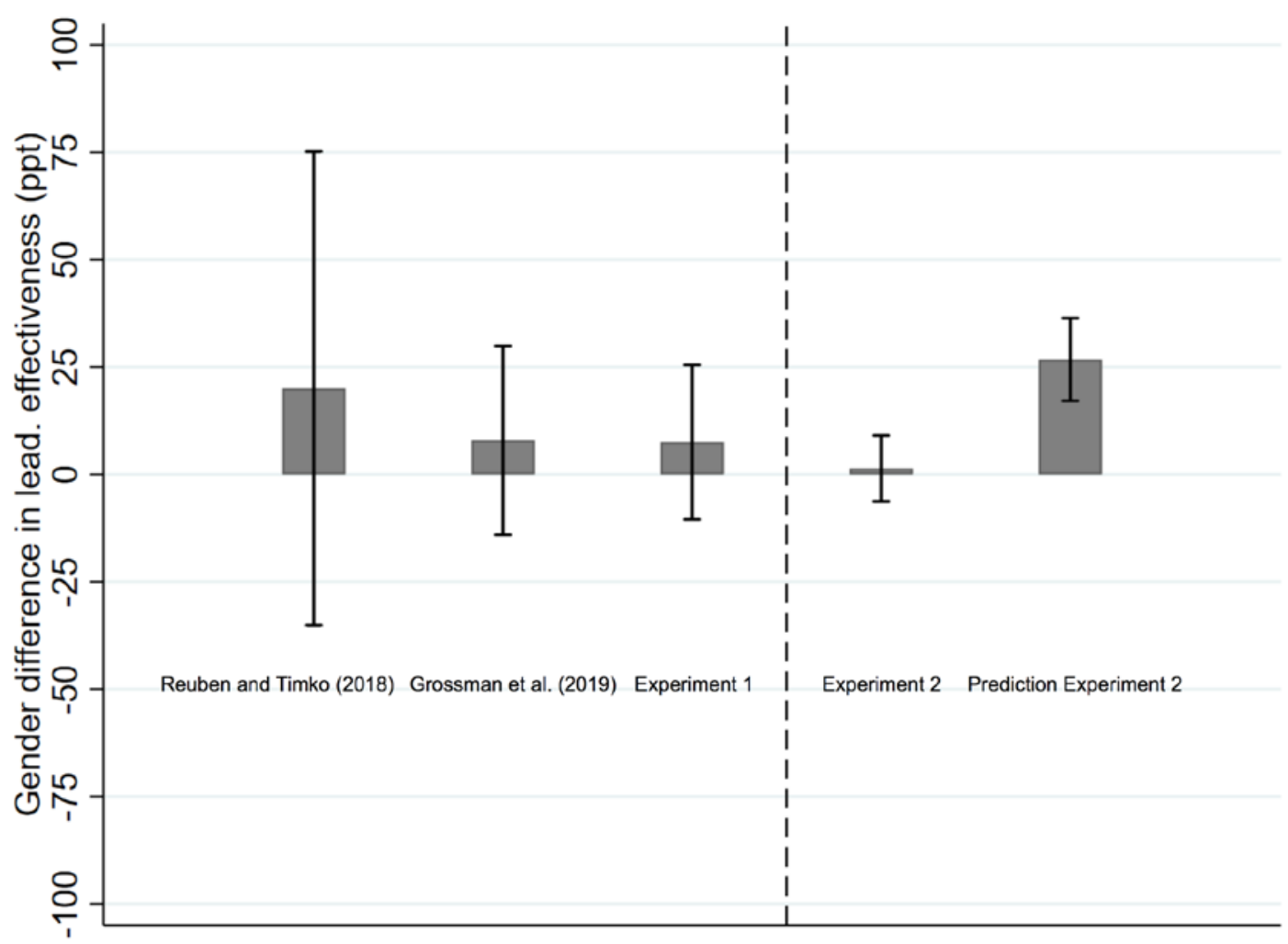

Notes: Gender difference in leader effectiveness is measured as the percentage point difference between the average success of a male leader minus that of a female leader in an experiment. Success ranges from $0 \%$ to $100 \%$ and is the outcome a leader achieved relative to what would be maximal success in an experiment. The bars show the average observed or predicted gender difference in leader effectiveness in gender visible conditions, along with 95-percent confidence intervals. The unit of observation is the leader. For the three experiments that are based on a repeated weak-link game (Reuben and Timko (2018), Grossman et al. (2019), Experiment 1), data from the first period after leaders were introduced is used. A sample of research economists predicted the effectiveness of female and male leaders in Experiment 2 (see Section 4.2.1)

We make several contributions to the existing literature. Among the papers in this literature only our experiments, together with the thesis chapter by Timko (2017), ${ }^{3}$ are designed to test the two mechanisms discussed above by varying the visibility of the leaders' gender to followers. With respect to comparisons in which the leader's gender is visible, we explore the gender gap in leader effectiveness using larger samples than concurrent studies, allowing us to estimate effects more precisely. Figure 1 illustrates this point and shows the observed gender gap in leader performance when the gender of the leader was visible to

\footnotetext{
${ }^{3}$ While similar to our paper in its approach, Timko (2017) comprises a total of 15 groups across 4 conditions (leader gender $\mathrm{X}$ leader gender visibility).
} 
followers in the two experiments presented in this paper, as well as the gender gaps estimated in Reuben and Timko (2018) and Grossman et al. (2019). ${ }^{4}$ The gender gap is measured as the percentage-point difference in the average success of male versus female leaders in an experiment, ranging from -100 to $100 .^{5}$ The first three bars show the estimated gender gaps in effectiveness in the gender visible condition of our Experiment 1 and in the studies by Reuben and Timko (2018) and Grossman et al. (2019), which all employ weaklink coordination games. In all three cases, men are more effective than women at obtaining efficient coordination, but the effects are not statistically different from zero.

Our Experiment 2 offers a novel design to detect even the slightest systematic differences in the persuasiveness of two groups of leaders. Our data from Experiment 2 thus provide a considerably more precise estimate of the null-result of no gender gap in leadership effectiveness. On an outcome space that ranges from -100 to 100 we estimate a gender effectiveness gap of only 1.4 percentage points with a 95-\% confidence interval of [-6.31, 9.07]. ${ }^{6}$ Importantly, we can compare this precisely estimated null-result in Experiment 2 with the predicted gender gap in effectiveness from the sample of gender researchers. As the final bar in Figure 1 reveals, they predicted, on average, an effectiveness gap of 26.8 percentage points when leader gender was visible to followers. This predicted gender gap lies well outside of the 95-percent confidence interval, as well as the 99-percent confidence interval, of actual effect sizes given our data. Therefore, by documenting the priors of a relevant research community and establishing results that are substantially different from these priors, our main finding provides valuable information (Abadie, 2020).

Our findings are important for correcting possibly mistaken beliefs about a gender gap in leader effectiveness and its source. Bertrand (2020) argues that a finding of no gender difference should be considered as valuable as a finding of a gender difference, since these null results can help to correct gender-stereotypical thinking. We began our research expecting to document that biased beliefs about the effectiveness of male and female leaders can generate real differences in their respective success in persuading follower teams to

\footnotetext{
${ }^{4}$ While similar in spirit, these two studies differ from ours along several dimension. Reuben and Timko (2018), for example, have additional treatment arms that vary the selection procedure of leaders. For the purpose of comparing effect sizes across studies, we selected the experimental conditions that are the most similar across the three studies. Section 1.3 of the Online Appendix provides more details on how we implemented the comparison.

${ }^{5}$ Specifically, in each experiment and for each leader we code the leader's effectiveness as a percentage point score, from 0 to 100, measuring the leader's outcome relative to maximal effectiveness. The relevant statistic in Figure 1 is the mean difference between the average score of male and female leaders.

${ }^{6}$ For this analysis, we use the large number of observations we collected in Experiment 2 in a very conservative way, treating each of the 96 leaders as a single observation.
} 
coordinate. However — surprisingly to us and to other researchers in economics — we find little evidence of such leadership gender gaps. Our results thus serve as a counterpoint to arguments that women should not lead in some environments, where buy-in from followers is critical, merely because the perception that they are less effective can be self-reinforcing.

The rest of this paper is organized as follows. The next section provides a review of related literature other than the closely-related work by Reuben and Timko (2018) and Grossman et al (2019) that we discuss above. Sections 3 and 4 present, respectively, our first and second experiment and discuss their corresponding results. Section 5 concludes and discusses important open questions.

\section{Related Literature}

Several academic fields have studied the effectiveness of male and female leadership. Meta-analyses of research in organizational behavior, based largely on subjective evaluations of leaders' abilities and effectiveness, find that the gender stereotype of the work context mediates the extent to which men and women are perceived as equally effective leaders (Eagly et al. 1995; Eagly and Karau 2002; Paustian-Underdahl et al. 2014). Generally, men are perceived as relatively more effective the more male dominated the organization (e.g., the military versus social service organizations) and the more male stereotyped the role.

Gipson et al. (2017) present an overview of the management research covering studies that investigate differences in organizational outcomes under male and female leadership. This primarily correlational line of work finds no consistent impact of the gender composition of high-level management positions such as the CEO or the company board, on, for example, financial outcomes or investments in CSR activities.

A growing body of studies in economics — often using natural experimentsinvestigates whether male and female leaders generate different collective outcomes, finding mixed results. For example, Chattopadhyay and Duflo (2004) make use of the random political reservations for women at the village level in India and find that female village leaders are more reactive to the priorities of female constituents. However, exploring the impact of gender quotas in candidate lists in local Spanish elections, Campa and Bagues (2017) find no impact of an increased share of women, neither with respect to the size nor the composition of public spending. Another example from the corporate sector is presented by Matsa and Miller (2013), who find companies that increased the share of female board members in response to the Norwegian gender quota to have higher labor costs and lower 
operating profits. However, these results are contradicted in Eckbo et al. (2016) who find no differences when extending the sample period.

More closely related to the question explored here-whether male and female leaders are more effective at influencing the behavior of followers-a recent strand of research uses experimental methods to evaluate reactions to male and female leadership. Gloor et al. (2020) and Chakraborty and Serra (2019) find that female leaders are evaluated more negatively and experience more backlash than male leaders, and that this effect is most pronounced in male dominated groups. ${ }^{7}$ A more mixed result is found in De Paola et al. (2018), who find that randomly appointed female team leaders devote more energy to improve team performance and achieve better results, but do not get better evaluations. Further mixed results come from experiments on public good games in which either female or male leaders make contribution recommendations. In a field experiment in India, Gangadharan et al. (2016) find that male villagers contribute less when their group has a female leader, whereas Grossman et al. (2015) observe no difference in contributions under male and female leadership in the laboratory.

\section{Experiment 1}

\subsection{Experiment Design}

Our first experiment employs the "turnaround game" paradigm introduced by Brandts and Cooper (2006), based on the weak-link coordination game (Van Huyck et al. 1990; Weber et al. 2001) in which a group with a history of coordination failure must be induced by a leader to coordinate on more efficient equilibrium actions. The experiment comprised three parts, with participants receiving instructions at the onset of each part. Payoffs were denoted in experimental currency units (ECU), with 150 ECU equal to CHF 1 ( $\approx 1$ USD).

Roles

At the beginning of the experiment, participants were randomly allocated to fixed sixperson groups. The instructions presented the groups as small "startups” with 5 "employees" and a "CEO." We used these labels to strengthen associations with male-dominated contexts. Employees played the weak-link coordination game across 16 periods, divided

\footnotetext{
${ }^{7}$ That leading roles may be more challenging for women is corroborated in recent work in economics which finds women to be less recognized for their expertise than men (Grunspan et al. 2016; Boring 2017; Mengel, et al. 2019; Sarsons et al., in press; Shurchkov and Geen 2019; Born et al., in press.). This effect seems to be particularly strong in stereotypically male fields of knowledge (Bohren et al. 2019; Bordalo et al. 2019).
} 
into Part 1 (periods 1-6) and Part 2 (periods 7-16). In Part 1, CEOs merely observed their firm's outcomes. In Part 2, they took an active role that we describe in detail below.

The Stage Game: The Weak-link Game

Following Brandts and Cooper (2006), in each period, employees independently decided how to allocate a total of 40 hours of work time (in increments of 10) between a "safe" and a "risky” project. We introduced a risky element to the standard weak-link game in order to further strengthen male-oriented contextual associations. For each hour allocated to the safe project, the employee earned 5 ECU with certainty. The payoff to the risky project depended on the minimum number of hours allocated to that project by any employee in the firm, meaning that allocations above the minimum were wasted. In addition, we introduced a random return, $r$, to the risky project. It could be either low or high with equal probability and was randomly determined in each period. ${ }^{8}$

The per period payoff of employee $i$ in group $g$ was thus determined by the formula:

$$
\pi_{i, g}=200-5 * h_{\text {risky }, i}+r * \min \left\{h_{\text {risky,g }}\right\}
$$

Where $h_{\text {risky, } i}$ denotes the hours that $i$ allocates to the risky project, and $\min \left\{h_{\text {risky,g }}\right\}$ is the minimum time allocated to the risky project by any of the five employees in group $g$.

At the end of each period, CEOs and employees were informed about the minimum number of hours spent on the risky project within the firm, their own payoff and accumulated payoffs across all previous periods. In addition, employees also observed how many hours they had invested in the risky project in that period and the CEO’s payoff.

\section{Payoffs in Part 1}

In Part 1 , the low rate of return was $r=5$ and the high rate of return was $r=6$. The specific payoffs in Part 1 were chosen to make efficient coordination in Part 1 highly challenging-investing in the risky project had only a minimally higher expected return (5.5), even when coordination was successful, than the return from the safe project (5). During this part, the CEO received a payoff equal to the average earnings of the employees.

\section{Part 2: Attempting a Turnaround}

Part 2 differed from Part 1 in two ways intended to give groups the opportunity to

\footnotetext{
${ }^{8}$ The variation in the rate of return was described to the participants as the result of factors, such as market competition, that were beyond the firm's control. The rate of return applied equally to all employees of a firm, was independently drawn across periods and was shown to subjects at the end of each period, after the employees had decided how to allocate their time.
} 
escape the inefficient coordination induced in Part 1. First, in Part 2 the CEOs were given the opportunity to direct the group to a more efficient equilibrium. Second, the randomly chosen rate of return to the risky project increased to 8 in case of a low return, and 10 in case of a high return.

\section{CEO Messages: Pre-play Communication to Employees}

At the onset of each period, the CEO sent a message to all 5 employees through a box that was available on the computer screen for 90 seconds. CEOs were free to write any messages, but were required to write at least 15 characters, and were instructed to avoid personal information and offensive language. The next stage started only after the CEO had sent a message. ${ }^{9}$ Employees read the CEO’s message before they decided how to allocate their time between the two projects.

After each leader sent their first message, in period 7, we asked them to predict their group's average investment in the risky project over all of Part 2. These guesses were incentivized for accuracy - the leader received 1 CHF if the actual average investment over Part 2, rounded to the nearest 10, equaled their guess.

\section{Payoffs in Part 2}

The employees' payoffs were calculated in the same way as in Part 1, except for the change in the return rates. The CEO's payoff in Part 2 consisted of a fixed payment and a variable component:

$$
\pi_{c e o, g}=150+r * \min \left\{h_{\text {risky,g }}\right\}
$$

Thus, the incentives of the CEO and the employees in a firm were perfectly aligned; both benefitted from higher minimum investment. However, in Part 2 the CEO earned more than the employees in groups that successfully coordinated on an equilibrium with high investment in the risky project. This asymmetry was intended to reflect patterns in managerial compensation outside the laboratory. The payoffs for both roles are shown in Appendix Table A1.

\section{Experimental Conditions}

The experiment comprised a 2x2 design, varying CEO gender and its visibility. Each session consisted of 24 subjects, who were randomly assigned to four groups. Each group

\footnotetext{
${ }^{9}$ If the CEO had not finished typing the message after 90 seconds, the CEO was reminded that the time was up. All CEOs had to send a message.
} 
in a session was randomized to one of the four different conditions. We recruited an equal number of women and men for each session to maintain an approximate gender balance.

The different conditions were implemented in Part 2. At the beginning of Part 2, all participants were informed that the employees in a firm may see the CEO's photograph. ${ }^{10}$ They were further informed that this occurred either for all employees in a firm, or for none of them, and that the CEO would not know whether the photograph was shown to the employees. ${ }^{11}$ In each experimental session, one group with a male CEO and one group with a female CEO was randomly selected to have the leader's photograph visible to employees, alongside the leader's statement, during all periods in Part 2. The employees in all groups remained anonymous to each other and to the CEO.

\section{Part 3: Additional Individual Measures}

In a final part of the experiment, all participants completed tasks intended to measure their explicit and implicit attitudes toward gender and leadership. We used the Gender and Authority Measure (GAM) (Rudman and Kilianski 2000) to measure participants' explicit preference for male versus female authorities through questions like, "I would feel more comfortable if the pilot of an airplane I was traveling on were male" or "I would rather work for a man than a woman.” With an Implicit Association Test (IAT) (Greenwald et al. 1998; Greenwald et al. 2003), we measured the strength of participants' tendency to more easily associate leadership with male or female gender. ${ }^{12}$

\section{Procedures}

The experiment was conducted in English at the Laboratory for Experimental and Behavioral Economics at the University of Zurich. In total, 600 participants from the University of Zurich and the Swiss Federal Institute of Technology in Zurich participated.

\footnotetext{
${ }^{10}$ Photographs of each participant were taken at the beginning of a session. The use of photographs was described in the invitation e-mail, and participants were reminded of this at the beginning of the study, before they consented to participate. All of the participants that showed up for a session consented to participate.

${ }^{11}$ Deliberately, we did not want CEOs to know whether their picture was revealed to followers. If they did, treatment could have systematically affected their communication.

12 The IAT asks participants to sort stimuli that appear sequentially on their computer screen with keys on their keyboard as quickly as possible into one of four categories. Stimuli represented combinations of the categories "male/female" and "leader/follower." Stimuli included, for example, "Leader, Chief, Director, Manager, Head” and "Follower, Assistant, Supporter, Helper, Aide.” Association strengths are measured by comparing the speed of categorizing stimuli of the four categories in two different sorting conditions (Greenwald et al. 2003). We slightly adapted the standard leadership and gender IAT protocol (see, e.g., Northouse 2012) to fit our subject pool better. Specifically, we replaced the English female and male names (e.g. Karen and Richard) with names that are very common in the 1990 birth cohort in German speaking countries (e.g. Julia and Tobias). We used the software Inquisit 5 to score the differences in response time and to administer the IAT. Section 1.1. of the Online Appendix describes additional individual measures that we collected, which, for space constraints, we do not report in the main text.
} 
Table 1 lists the number of participants in the different conditions. Our sample comprises 100 groups with 50 male and 50 female leaders. We oversampled groups in which the gender of the leader was known.

Table 1. Session Overview and Number of Observations

\begin{tabular}{|lccc|}
\hline Treatment & Groups & Leaders & Followers (men, women) \\
\hline Female Leader Gender Visible & 30 & 30 & $150(79,71)$ \\
Male Leader Gender Visible & 30 & 30 & $150(75,75)$ \\
Female Leader Gender Blind & 20 & 20 & $100(56,44)$ \\
Male Leader Gender Blind & 20 & 20 & $100(44,56)$ \\
\hline Total & 100 & 100 & 500 \\
\hline
\end{tabular}

All instructions are provided in the Online Appendix. Before Parts 1 and 2, participants also answered comprehension questions; the study only advanced after all participants had answered the questions correctly. The experiment was programmed in ztree (Fischbacher 2007). All periods were paid out and average earnings were 44.76 CHF (including a 15 CHF show-up fee).

\section{Coding of CEO Messages}

After the main data was collected, we hired 10 native English speakers from the same subject pool as the participants (but who had not participated in the study) to code the messages sent by the CEOs, and to rate characteristics of the CEOs' pictures. The research assistants categorized the content of the messages the leaders sent according to 13 predetermined categories, similar to those employed by Brandts et al. (2015) (see Table A4 in the Appendix for a list of the categories and summary statistics).

\subsection{Results}

In this section, we first explore whether participants in our sample held stereotypical views about gender and leadership, based on their responses to the individual measures in Part 3. Next, we briefly consider behavior in Part 1 to confirm that most of the groups converged to the inefficient equilibrium of the coordination game. We then turn to our primary focus-whether male and female leaders obtain different outcomes in the second part of the experiment.

\subsubsection{Gender Stereotypes About Leadership}


We measured participants' stereotypes about gender and leadership in two ways. In the IAT measure, scores range from (2), indicating a stronger association between maleness and leadership to (-2), implying a bias in the opposite direction. Among the followers in our sample, we find a tendency to associate leadership with maleness. The mean IAT score is 0.33, and $49 \%$ of followers exhibit a moderate to strong bias (see Appendix Figure A1). The Gender and Authority Measure ranges from 1 to 5, with 3 indicating a neutral stance and higher scores indicating preference for male authorities. On average, this measure also indicates a slight preference for male authorities, with an average score of 3.41 which is significantly larger than 3 (t-test p-value $<0.001$, see Appendix Figure A2). We find no evidence that treatment impacted either the IAT or the GAM.

We also find that women held more pessimistic beliefs about their own effectiveness as leaders than men. At the beginning of Part 2, leaders were asked to predict the average investment in the risky project in Part 2 for their group. Female (male) leaders believed themselves to generate, on average, an investment of 27.2 (32.8) hours in the risky project, and the 5.6 hours difference is statistically significant ( $\mathrm{p}$-value $=0.010$, two-sided t-test). ${ }^{13}$

To summarize, we find evidence of at least a small level of bias against female leaders among followers, which is also present in leaders' beliefs about their own performance. Next, we examine whether such perceptions translate into differential leader effectiveness.

\subsubsection{Group Outcomes in Part 1}

In the final period of Part 1, the overwhelming majority of groups in our sample, 84\%, coordinated on the inefficient, but less risky, equilibrium in which all employees invest 0 hours in the risky project. The average investment in period 6 is below 4 in all conditions. ${ }^{14}$ A Kruskal-Wallis test fails to reject the null hypothesis that the distributions of group outcomes are similar across conditions both over all of Part $1(\mathrm{p}=0.177)$ and in the final period of Part 1 ( $\mathrm{p}=0.083$ ). Hence, in period 7 , the majority of group leaders faced the task of moving their followers away from a recent history of inefficient coordination.

\subsubsection{The Impact of Leader Gender on Group Performance}

We start by looking at group outcomes in period 7, when followers responded to their leaders' advice for the first time. Figure 2 presents our main measure of leadership effectiveness - the average number of hours a group invests in the risky project. In period

\footnotetext{
${ }^{13}$ The actual average outcome was 30.26 and 31.92 hours for female and male leaders respectively, meaning that female leaders were underconfident with respect to their actual performance, while male leaders were slightly overconfident.

14 Table A2 in the Appendix shows the mean investment in Periods 1-6 and Period 6 in all conditions.
} 
7, groups led by a woman invest an average of 25 hours in the risky project in both the gender visible and the gender-blind conditions. Under male leadership, groups invest an average of 31 hours in the risky project in the gender-blind condition and an average of 28 hours in the gender visible condition. Neither of these gender gaps in leadership effectiveness in period 7 is statistically significant (two-sided t-tests on equality of means; gender visible: $\mathrm{p}$-value $=0.407$, gender invisible: $\mathrm{p}=0.136) .{ }^{15}$

Figure 2 also presents how the average group performance evolved over all 10 periods of Part 2. Across these periods, the average effect of having a woman as a leader compared to a man is 0.15 fewer hours invested in the risky project in the gender-blind condition (pvalue $=0.967)$ and 2.7 in the gender visible condition ( $p$-value $=0.419) .{ }^{16}$ Thus, we find only small and statistically insignificant differences between groups led by men or women.

\section{Figure 2. Average Group Investment by Condition}

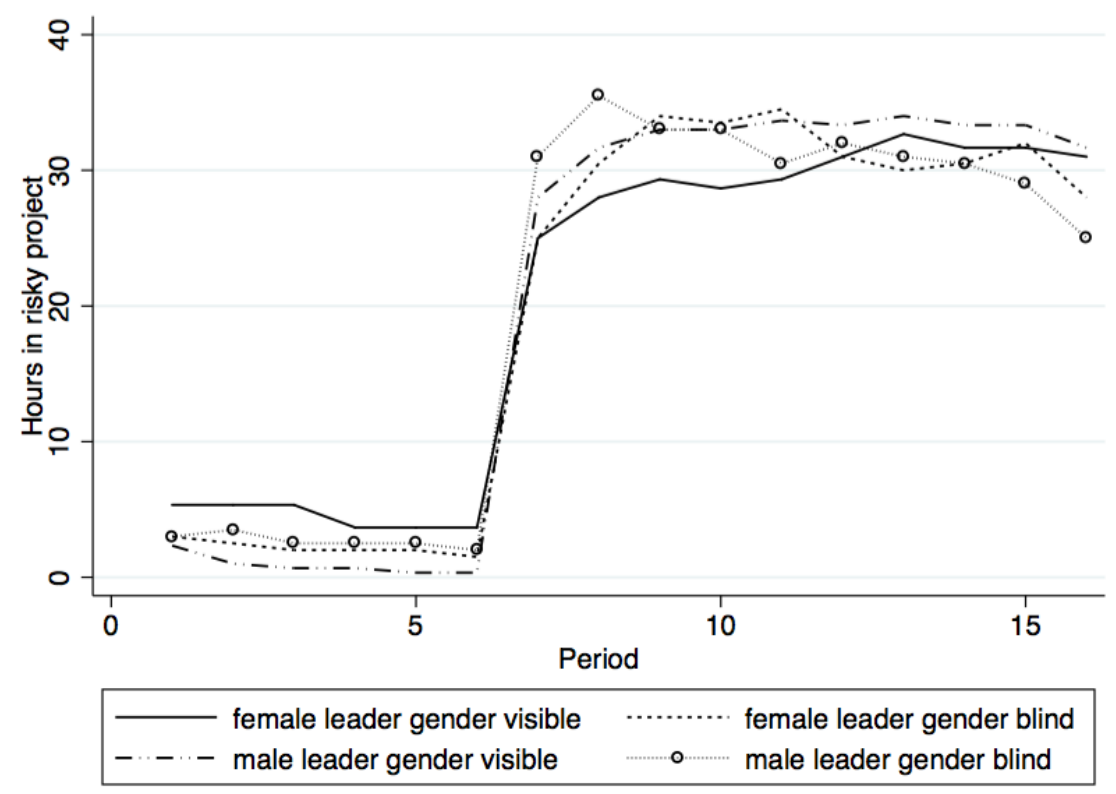

The regression analysis in Table 2 shows that the absence of a leader gender effect on outcomes is robust to controlling for differences in group outcomes in Part 1 and leader recommendations. ${ }^{17}$ In the first two specifications, we use the minimum hours invested in

${ }^{15}$ Appendix Figure A3 shows the cumulative distributions of group investment in period 7 by condition. A Mann-Whitney test fails to reject the null hypothesis of similar distributions $(p=0.399$ for gender visible, $\mathrm{p}=0.096$ for gender blind).

16 This result is confirmed using a Wilcoxon-Mann-Whitney test: we find no evidence of any differences in the distributions of group outcomes over the whole of Part 2 under male and female leadership (gender blind: $\mathrm{p}=0.34$, gender visible: $\mathrm{p}=0.25$ ).

${ }^{17}$ Recall that independent raters coded each leader's message in a period for content. Table A4 in the Appendix presents a list of each message category and the corresponding frequencies by gender. In period 7, men were 
the risky project in a group in period 7 as the dependent variable and control for the gender of the leader, whether the leader's portrait was shown and their interaction. We use the variable Group performance in Part 1, which takes the value of the highest minimum effort in a group during the final three periods of Part 1, to control for the history of play in Part $1{ }^{18}$ In specification 2 we also add a control for the numeric investment recommendation of the leaders in Period 7, whenever such a specific request was made. ${ }^{19}$

Table 2. Impact of Gender Leader on Group Performance

\begin{tabular}{|c|c|c|c|c|}
\hline & \multicolumn{4}{|c|}{$\begin{array}{l}\text { OLS regressions predicting group performance } \\
\text { (minimum hours invested in risky option) }\end{array}$} \\
\hline & $\begin{array}{c}(1) \\
\text { First period } \\
\text { of Part } 2\end{array}$ & $\begin{array}{c}(2) \\
\text { First period } \\
\text { of Part } 2\end{array}$ & $\begin{array}{c}\text { (3) } \\
\text { Average for } \\
\text { all of Part } 2\end{array}$ & $\begin{array}{l}(4) \\
\text { All periods in } \\
\text { Part } 2\end{array}$ \\
\hline Female leader & $\begin{array}{l}-5.739 \\
(4.165)\end{array}$ & $\begin{array}{l}-0.017 \\
(3.525)\end{array}$ & $\begin{array}{c}-0.091 \\
(3.851)\end{array}$ & $\begin{array}{l}-0.091 \\
(3.535)\end{array}$ \\
\hline Leader visibility & $\begin{array}{r}-2.044 \\
(3.831)\end{array}$ & $\begin{array}{c}0.329 \\
(3.080)\end{array}$ & $\begin{array}{l}1.666 \\
(3.544)\end{array}$ & $\begin{array}{l}1.666 \\
(3.615)\end{array}$ \\
\hline $\begin{array}{l}\text { Female leader } \mathrm{X} \\
\text { Leader visibility }\end{array}$ & $\begin{array}{c}1.175 \\
(5.457)\end{array}$ & $\begin{array}{l}-1.215 \\
(4.579)\end{array}$ & $\begin{array}{l}-2.928 \\
(5.046)\end{array}$ & $\begin{array}{l}-2.928 \\
(4.931)\end{array}$ \\
\hline Part 1 group performance & $\begin{array}{l}0.521^{*} \\
(0.270)\end{array}$ & $\begin{array}{c}0.091 \\
(0.243)\end{array}$ & $\begin{array}{c}0.118 \\
(0.250)\end{array}$ & $\begin{array}{c}0.118 \\
(0.204)\end{array}$ \\
\hline $\begin{array}{l}\text { Leader recommendation } \\
\text { (number of hours) }\end{array}$ & & $\begin{array}{c}0.778 * * * \\
(0.107)\end{array}$ & & \\
\hline Constant & $\begin{array}{c}29.70 * * * \\
(3.020)\end{array}$ & $\begin{array}{c}2.287 \\
(4.751)\end{array}$ & $\begin{array}{c}30.76^{* * *} \\
(2.793)\end{array}$ & $\begin{array}{c}30.76^{* * *} \\
(2.780)\end{array}$ \\
\hline $\begin{array}{l}\mathrm{N} \\
\text { (groups) }\end{array}$ & 100 & 82 & 100 & $\begin{array}{l}1000 \\
(100)\end{array}$ \\
\hline$R^{2}$ & 0.0284 & 0.3924 & 0.0032 & 0.0072 \\
\hline
\end{tabular}

Notes: Female leader is an indicator for whether the leader $l$ of a group is female and Leader visibility indicates whether the portrait was shown to followers. Female leader $X$ Leader visibility interacts these two variables. Group performance in Part 1 is the highest group equilibrium played-the maximum of the minimum hours a group invested in the risky project-over the last three periods of Part 1. Leader recommendation (number of hours) records the specific numeric investment recommendation the leader gave to followers, whenever such a specific request was made. Standard errors in parentheses (clustered at the group level in model 4) *Significant at the $10 \%$ level,** at the $5 \%$ level, *** at the $1 \%$ level.

more likely to recommend investing 40 in the risky project (72 vs. 52 percent) and to provide explanations for suggested effort ( 86 vs. 62 percent), while women were more likely to provide ambiguous suggestions recommending higher effort ( 24 vs. 8 percent). In Online Appendix 1.2 we further investigate differences in leader messages and their impact by gender.

${ }^{18}$ With this variable, we control for the experience of successful coordination in the three periods that immediately precede the play of Part 2. For robustness, we also attempt to control for group outcomes in Part 1 in different ways - e. g. the group hours in the risky project in period 6 - which does not change our results. ${ }_{19}$ In later rounds, there are fewer and selected instances in which leaders gave numeric investment recommendations since many participants stopped doing this once their group was coordinated at 40 hours investment in the risky project. This is why we only control for investment recommendations when we predict minimum hours in risky project in period 7. Not all leaders gave numeric recommendations in period 7 so our sample for this analysis is a subset of the full sample. 
In specifications 3 and 4 we extend the analysis, using as dependent variables first the average group outcome across all of Part 2 and then all 10 observations for a group across Part 2, clustering observations at the group level. In neither of these specifications do we find significant effects of leader gender or leader gender visibility on how well groups perform in Part 2. ${ }^{20}$

\subsection{Discussion of Experiment 1}

Our results suggest that, contrary to our motivating hypothesis, women are no less effective at inducing change to an efficient, but risky, equilibrium in a weak-link coordination game. While the point estimates of the gender effect are in the hypothesized direction, they are small to moderate in magnitude and never statistically significant. This absence of a gender effect is true both when leaders' gender is not known and when it is known, and whether we consider group outcomes or individual behavior.

We were surprised by these results. As we note earlier, our participants express some degree of bias toward associating maleness with leadership, consistent with prior research in psychology. Indeed, given that other research teams concurrently investigated the same question using similar designs suggests that others shared our expectation. Moreover, our design included elements intended to strengthen associations with male stereotypes.

The absence of the hypothesized results may arise due to at least two reasons. Either both we and others fail to detect any gender bias in how followers respond to leaders because it does not exist, or because the contexts studied are not well suited to detect such differences. In fact, while the weak-link and turnaround games have been widely used to study leadership, the games may not be ideal for detecting discrimination favoring one kind of leader over another. In these games, followers' always benefit if they coordinate on following a leader, meaning that they have a clear economic interest not to discriminate against any leader. Moreover, a follower wants to follow the leader's recommendation whenever she thinks the likelihood that all others will do so is above a specific threshold. Thus, differences in the effectiveness of leaders, even if substantive, will only be detected if these likelihoods lie on opposite sides of this threshold. Given the relatively high rates of

\footnotetext{
${ }^{20}$ Potentially, there is more variation in how individual followers respond to female and male leaders than captured by the group performance measures in the previous section. In Appendix Table A3, we report the same regressions as in specification 1 and 2 in Table 2 using the individual instead of the group as the unit of observation. We also report the results of specification 1 for men and women separately. We again fail to reject the null hypothesis of no gender gap in leadership effectiveness in all regressions and for either gender of followers.
} 
leader effectiveness in our experiment, the above concerns provide a potential interpretation of our null result.

To make the above argument more concrete, Appendix B1 presents a simple model of behavior in coordination games when followers are encouraged to select an action by a leader with a given level of persuasiveness. This analysis identifies the above limitations to using weak-link coordination games to study discrimination against leaders of different groups. It also suggests an alternative design as a more precise test of the relative persuasiveness of male and female leaders. Instead of having each group of followers decide whether or not to follow one leader, each group has to coordinate on following one of two leaders, one male and one female. In this case, the followers' expected payoffs are higher by following any leader perceived as even slightly more persuasive. Thus, even a very slight tendency to believe that male leaders will receive more support from other followers should result in a clear preference for that leader type.

\section{Experiment 2}

Motivated by the above considerations, we designed a game in which followers have to coordinate on following the recommendations from one of two leaders, with a focus on the case in which leaders differ with respect to their gender.

\subsection{Design of Experiment 2}

In the second experiment, participants were assigned the role of either a CEO of a small start-up or an Investor. CEOs were incentivized to persuade followers to invest in their firm. In order to obtain CEOs directives, initial sessions comprised only CEOs, who used these sessions to craft a message to Investors in order to attract their investment. Subsequent sessions consisted only of Investors.

This second experiment retained factors from the first, such as an underlying coordination game and the importance of second order beliefs about leader effectiveness. It also retained the professional context and underlying riskiness of payoffs, intended to, if anything, strengthen associations with male stereotypes. Finally, as in Experiment 1, half of all Investor pairs also saw the portraits of the two CEOs above their messages.

\section{The Leader Competition Game}

Across several rounds, pairs of Investors, anonymous to each other, played the coordination game described below, framed as an investment task. They saw the messages of two competing CEOs displayed in random order on their screens and had to choose, 
privately and simultaneously, in which of the two firms to invest. Investors played a purematching coordination game in which they earned money only if they both chose to invest in the same firm. A CEO earned money in a round only if their message persuaded both Investors to invest in his or her firm.

Below we describe the two kinds of sessions in detail.

\section{The CEO Sessions}

When arriving at a session, participants in the role of CEO were given the full instructions for the game. This included a description of their role as CEO and the role that would subsequently be performed by Investors. CEOs were informed that they could think of their role as being the CEO of a small start-up firm. The first and main task for each CEO was to draft a message to the Investors in order to convince them to invest in that CEO's firm. In the instructions, we aimed to further strengthen associations with male stereotyped contexts by stressing the competitive aspect of the game-e.g., by referring to the other CEO with which they would be paired as the CEO of a "competing firm.” The CEOs were further told that the Investors would see their message and that of the CEO of the competing firm when making their decisions in each round. In addition, the computer would randomly determine whether to show the CEOs’ photos along with their messages, and if photos were shown, the photos of both CEOs would be shown.

Each CEO had 40 minutes to write a message, and was restricted to use between 60 and 700 characters (about 10-100 words). We asked all CEOs to refrain from using personal identifying information or offensive language. Two of these messages are reproduced in Appendix Figure A4. Overall, participants drafted their message with great care. ${ }^{21}$

While drafting their messages, CEOs were called on, one at a time, to have portrait photograph taken. The photos were taken by an experienced photographer in a different room with professional photo equipment. Participants were instructed to pose like they would in a photo for their curriculum vitae. The photographer ensured that the portraits were very similar in terms of composition and facial expression.

At the end of the session, after writing their messages, the CEOs were asked to choose 3 out of 6 possible "products" that their firm would develop and sell. The products were represented by 6 letters shown on the screen (e.g., "Product X”), and CEOs simply clicked on three products to make their choice. Before the participation of the Investors, we

\footnotetext{
${ }^{21}$ The average length of a message is 451 characters (about 64 words) and the overall rate of misspelled words in all messages is very low, at 0.014 , in an environment without an automatic spell checker. This likely reflects the participants' effort at attempting to type convincing messages.
} 
randomly drew 1 of the 6 products to be the "successful" product for this study. This choice was relevant for the payoff of Investors who earned extra money from coordinating their investments in firms where the CEO had also selected a successful product. While this part of the study is simply a random lottery, we implemented it in order to add an element of risk, to provide the CEOs with a payoff relevant choice and to allow them to argue in their statements about their abilities to make better choices.

Participants in the role of CEO received a show-up fee of CHF 15. In addition to the show-up fee, CEOs earned CHF 2 for every game in which their message was used and in which both Investors invested in the CEO’s firm. CEOs knew that their message would be used in several games and that they would be paid according to the behavior of Investors in a randomly selected subset of 24 of these games. This performance-based part of their payment was mailed to the CEOs after the completion of the Investor sessions. The final payoff of a CEO was thus the show-up fee plus the sum of the payments across 24 games in which the CEO's message was used, with the total ranging from CHF 15 to 63.

\section{The Investor Sessions}

After all CEOs had participated in the study, a new set of participants were invited to take part as Investors. As with the CEOs, subjects in the role of Investor first went through the full instructions for the study, explaining the role of the CEOs who had participated earlier, as well as the role of the Investors.

Investors then played 24 rounds of the coordination game described above. In each round, Investors were randomly assigned a new pair of CEOs. An Investor never encountered the same CEO more than once. Investors were randomly re-matched in each round and could be matched with the same Investor more than once. However, Investors never knew the identity of their matched counterpart, and did not know whether they had met a particular Investor before. Moreover, Investors received no feedback on any choices that were made until the end of the session, when they saw their earnings.

Investors made their investment decisions by clicking on one of the two competing firms presented on their screen (as shown in Appendix Figure A4). They were told that the order in which CEOs were displayed on their individual screen was random and that they could therefore not use screen position as a way to coordinate.

For each Investor, one of the 24 games was randomly selected for payment. If the Investors did not coordinate in this game both Investors both earned 0 . If they coordinated, but the CEO had chosen an unsuccessful product, they earned 15 CHF. Finally, if they 
coordinated, and the CEO had chosen a successful product, they earned 25 CHF. These incentives were paid in addition to a 15 CHF show-up fee.

In a final questionnaire, we collected the same individual measures regarding explicit and implicit gender stereotypes on leadership as in Experiment 1, the IAT and the GAM (see section 3.1). We also asked basic demographic questions, e.g., about age and gender.

\section{Experimental Conditions}

As in Experiment 1, we varied whether the CEOs matched with Investors in a game were male or female and whether gender was observable to Investors. The experimental conditions varied within-subject for Investors, with different treatment configurations across games. The randomization of the CEO pairs was stratified such that, in expectation, 2/3 of matches would involve one male and one female CEO. In the experiment, $61.2 \%$ $(\mathrm{N}=940)$ of all investment games involved a male and a female CEO, 19.7\% ( $\mathrm{N}=302)$ involved two female CEOs, and 19.1\% (N=294) involved two male CEOs.

In exactly half of all investment games (768 of 1536), the portraits of the two CEOs were displayed along with their messages. This balance was achieved by letting two sets of Investor pairs play the investment game with each randomly formed CEO pair. One of these Investor pairs had access to the CEOs' portraits and messages, while the other pair only saw messages. Thus, for each CEO pair, we have one game with photographs and one without.

\section{Experiment Procedures}

Experiment 2 was conducted in English at the Laboratory for Experimental and Behavioral Economics at the University of Zurich. In total, 224 participants from the University of Zurich and the Swiss Federal Institute of Technology in Zurich took part in the study.

The CEO sessions were programmed in Qualtrics, and we collected the data for 96 participants in the role of CEO, half of them women, on two days. To facilitate taking the portrait photographs, sets of four participants were recruited to arrive in 15-minute intervals. Upon arrival, participants read the instructions available as a printout on their work terminal. Participants could only start drafting the message to Investors once they had correctly answered several comprehension questions.

About two weeks after the CEO sessions, we conducted a total of four Investor sessions with 32 participants per session. All 128 participants listened to a recording of the instructions before the experiment started, and the experiment started only once all 
participants had correctly answered a set of control questions. The Investor sessions were programmed in Ztree (Fischbacher 2007).

The instructions for CEOs and Investors are provided in Online Appendix. The sessions for the CEOs and the Investors lasted, respectively, 1 and 1.25 hours. CEOs earned an average of $44.8 \mathrm{CHF}$ and Investors earned 30.8 CHF.

\subsection{Results}

\section{Establishing Priors: Expert Prediction Task}

Before presenting results, we provide estimates of the prior beliefs held by a set of experts regarding the outcomes in Experiment 2. DellaVigna et al. (2019) argue that collecting predictions before communicating experimental results may mitigate hindsight and publication bias and help assess the novelty and information value of empirical results.

In October 2018, before we shared the results from this study, we asked participants at a workshop on gender and economics to predict the results. A one-page handout summarizing the experiment (shown in Online Appendix 2) was distributed to the workshop participants. They had about 30 minutes to make a prediction regarding what percent of the time followers who faced two competing leaders of opposite sex invested in the male leader's firm when gender was (i) not known and (ii) known. Participation was voluntary and incentivized. For each prediction, we selected the person whose guess was closest in absolute value to the actual percentage; that person received 50 Euros. Almost every workshop participant present took part and we received a total of 54 answers.

The average prediction for the gender-blind condition is that male CEOs are followed to the same extent as females, in $49 \%$ of the cases. However, for the gender visible condition, the average prediction is that 63 percent of followers will follow the male CEO. Thus, researchers expected male and female CEOs to write messages that were equally effective, but expected followers to rely on gender stereotypes about leadership to coordinate their investments. Put differently, this sample of researchers expects our experiment to reject the null hypothesis in favor of H1b, that performance differences of female and male leaders arise due to self-confirming perceptions of leadership quality.

\subsubsection{Do Messages and Photographs Influence Coordination Rates?}

If followers were to simply randomize over the two investment options, the expected coordination rate would be 0.5 . Table 3 presents the empirical coordination rates in our experiment, by treatment. The average coordination rate is 0.592 in the gender-blind 
condition and 0.642 when gender is visible; both outcomes are significantly more frequent than the 0.5 benchmark $(\mathrm{p}<0.001$ for both conditions, test of proportions, $n=768$ per condition). These results indicate that leaders are instrumental for successful coordination and that Investors pay attention to the leaders when they make an investment decision. Moreover, the coordination rate in the gender-visible condition is significantly higher than when gender is blind ( $\mathrm{p}$-value $=0.005$, test of proportions, $\mathrm{n}=1556$ ), ${ }^{22}$ suggesting that followers rely on characteristics in the pictures to coordinate, over and above the message content.

Table 3. Rate of Successful Coordination by Treatment

\begin{tabular}{|c|c|c|c|c|}
\hline \multicolumn{2}{|c|}{ Treatment } & $\begin{array}{c}\text { Average Rate of } \\
\text { Coordination }\end{array}$ & $\begin{array}{c}\text { p-value } \\
\text { (difference from 0.5) }\end{array}$ & Obs. \\
\hline \multirow{4}{*}{ Gender blind } & mixed-gender leaders & 0.602 & 0.0000 & 470 \\
\hline & 2 female leaders & 0.610 & 0.0072 & 151 \\
\hline & 2 male leaders & 0.544 & 0.2836 & 147 \\
\hline & Total & 0.592 & 0.0000 & 768 \\
\hline \multirow{4}{*}{$\begin{array}{c}\text { Gender visible } \\
\text { (messages + } \\
\text { pictures) }\end{array}$} & mixed-gender leaders & 0.626 & 0.0000 & 470 \\
\hline & 2 female leaders & 0.722 & 0.0000 & 151 \\
\hline & 2 male leaders & 0.612 & 0.0065 & 147 \\
\hline & total & 0.642 & 0.0000 & 768 \\
\hline
\end{tabular}

\section{Are There Gender Differences in Leader Persuasiveness?}

Before we explore whether the gender of the leader impacts their ability to gain support from followers, we report on followers' implicit and explicit biases regarding gender and leadership. Briefly, we find very similar results as in Experiment 1. Both, the average score in the IAT (0.26) and the GAM (3.5) indicate a slight bias in favor of male leaders, with $40 \%$ of the followers revealing a moderate to strong bias in implicitly associating leadership more with men than with women (see Appendix Figures A1 and A2).

To test our main hypotheses, we only consider data from mixed-gender pairings, pitting male and female leaders against one another. In the gender-blind condition, followers chose to invest in the project promoted by the male CEO $50.0 \%$ of the time. The corresponding number for the gender visible condition is $50.4 \%$. This supports our null hypothesis of no leader gender gap in persuasiveness against either alternative hypothesis

\footnotetext{
${ }^{22}$ Note that the underlying random leader pairings are exactly the same in these two samples.
} 
of greater persuasiveness by male leaders. A test of proportions against the 0.5 benchmark confirms that neither difference is statistically significant (p-values of test of proportions against 0.5 benchmark: $\mathrm{p}=0.9480$ (gender blind), $\mathrm{p}=0.7941$ (gender visible), $\mathrm{n}=940$ in both conditions). ${ }^{23}$ Hence, also in Experiment 2 we find no substantial gender gap in leadership persuasiveness - with or without gender being visible - and with a much more precisely estimated null effect. ${ }^{24}$

We can also investigate the heterogeneous effectiveness of individual leaders. For each of the 96 leaders in our sample, we estimate that leader's persuasiveness using the empirical rate at which they are followed when they compete against a leader of the opposite sex. Figure 3 displays the empirical cumulative frequencies obtained separately for male and female leaders. Panels (a) and (b) show, respectively, the empirical distributions of leader persuasiveness in the gender blind and gender visible conditions. For both genders, we observe substantial heterogeneity in leader persuasiveness. However, in both cases, the distributions of male and female leaders look quite similar.

Figure 4 further illustrates the precision with which we estimate no gender gap in leader effectiveness. ${ }^{25}$ The figure shows the mean difference in the persuasiveness of individual male and female leaders. The vertical axis ranges from -100 percentage points (corresponding to female leaders always being chosen over male leaders) to 100 percentage points (corresponding to male leaders always being chosen over female leaders). In the gender-visible condition, the average gender gap is 1.38 points with a $95-\%$ confidence interval of $[-6.31,9.07]$; in the gender-blind condition it is 0.14 points with the corresponding confidence interval of [-6.98, 7.27]. ${ }^{26}$

We contrast this with the predicted gender gap in persuasiveness based on our sample of researchers. The expert predictions expect the null hypothesis to hold in the gender-blind

\footnotetext{
${ }^{23}$ Appendix Table A6 reports regression analysis of the probability that a leader is followed, as a function of the leader's gender, whether the leader's gender is visible, the follower's gender and characteristics of the leader's message. None of the treatment variables are statistically significant.

${ }^{24}$ Appendix Figure A5 shows the power curve of the two-sided one-sample test of proportions to reject the null hypothesis that women are followed at the same rate as men, at the 0.05 level of statistical significance or higher, given 940 independent decisions of whether to follow the female leader. For example, for the average rate predicted by research economists (37 percent), this test has a power very close to 1.

${ }^{25}$ As an alternative test of our second alternative hypothesis, we can also exploit the fact that for each mixedgender pair of leaders we observe how two pairs of followers - one pair in the gender-blind condition and one in the gender visible condition-respond to those leaders' directives (see Table A5 in the Appendix). Comparing the rate at which leaders persuaded followers across conditions, in $30.4 \%$ of the cases, a female leader was more persuasive in the gender visible condition compared to the gender-blind condition, in 30.7\% of the cases there was a move in the opposite direction, and in $38.9 \%$ of the cases there was no change.

${ }^{26}$ These confidence intervals are based on the t-distribution, treating each of the 96 leaders as an independent observation.
} 
comparison, with an average predicted persuasiveness gap of -2.38, but expect a gap of 26.8 when gender is visible (i.e., 63.4 - 36.6). Clearly, our data reject this predicted effect size for the gender visible scenario.

Figure 3. Rate at Which Leaders in Mixed-gender Pairs are Followed by Treatment: Cumulative Frequency

a. Gender Blind

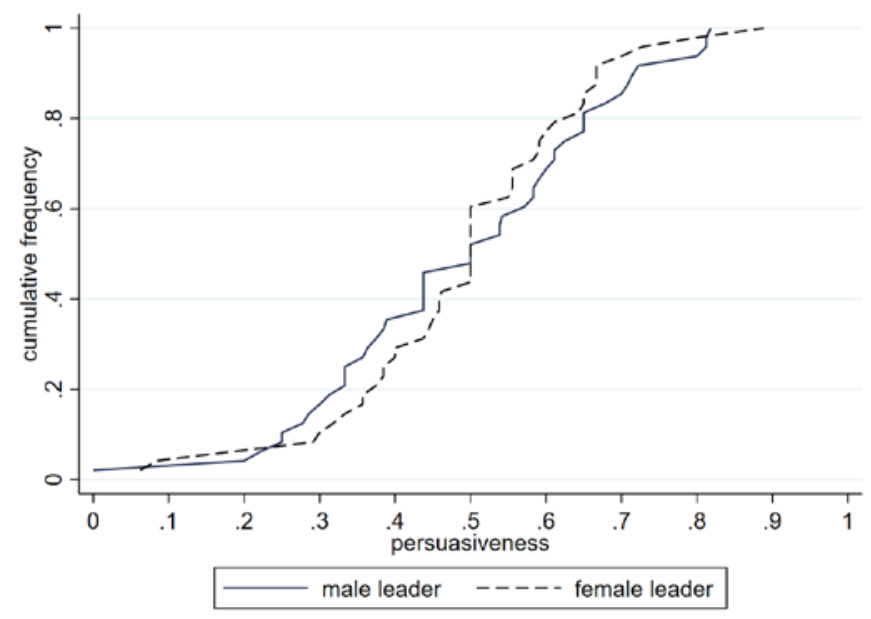

b. Gender Visible

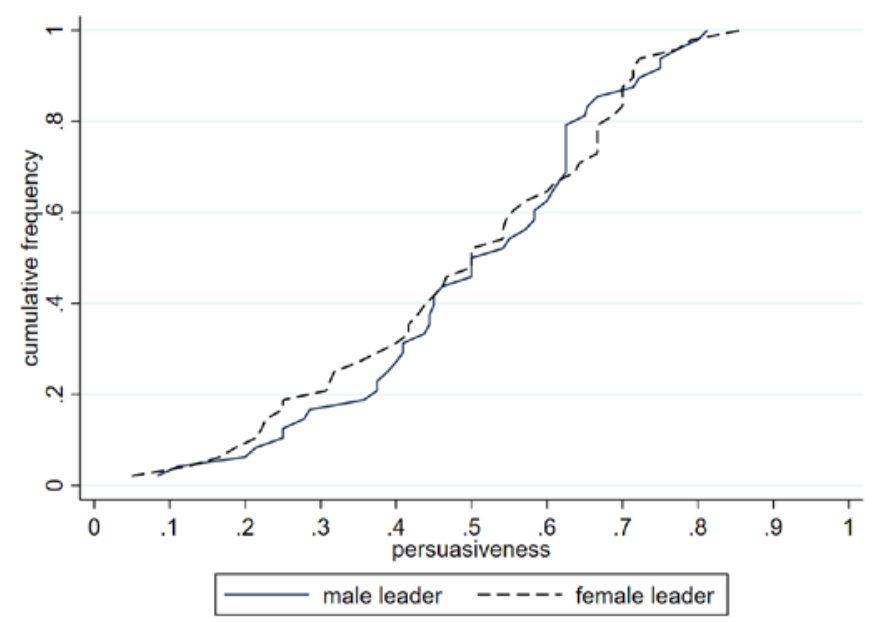


Figure 4. Observed and Predicted Gender Gaps in Leader Effectiveness

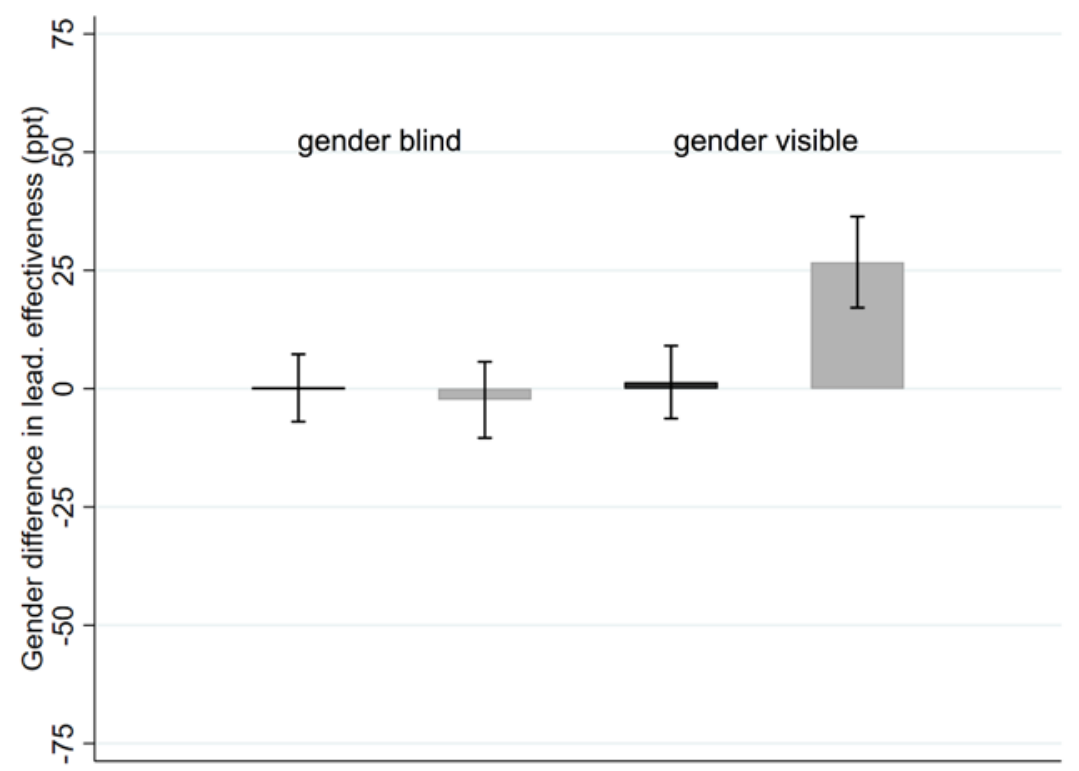

Notes: For each experimental condition, the black bars to the left depict the average observed and the grey bars to the right the average predicted gender gap in leadership effectiveness. Gender difference in leader effectiveness is measured as the percentage point difference in the average success of male and female leaders, with bars representing 95-\% confidence intervals. Success ranges from $0 \%$ to $100 \%$ and corresponds to the rate at which a leader is followed when matched with a competing leader of the opposite sex.

\subsection{Discussion of Experiment 2}

We designed Experiment 2 to detect even slight differences in the persuasiveness of male and female leaders. Despite this stronger test, Experiment 2 replicates the null results obtained in Experiment 1 and in earlier research, although with considerably more precision. The results from the gender-blind condition indicate that male and female leaders communicate equally persuasively, and we find no indication that stereotypes impact followers' coordination decisions in the gender visible condition. Our survey of experts' expectations establishes that this null result is surprising, relative to the priors of researchers with expertise in the area of gender economics.

\section{Conclusion}

We present results from two experimental studies designed to test the hypothesis that female leaders are less effective than men at motivating coordinated responses by followers. In both experiments, leaders send messages to followers in which they direct followers toward specific actions in simultaneous-move coordination games. We add contextual features to the games in order to enhance the perception of a stereotypically male domain. In order to test two channels through which differential leader persuasiveness may operate, 
we experimentally vary the gender of the leader and whether the gender is observed by followers.

In our first experiment, followers play a weak-link coordination game in which a safe investment option guarantees a fixed amount of money, independent of the actions of other followers. Leaders recommend to followers an alternative action that entails greater risk but also a potentially high return. Thus, leader effectiveness involves obtaining coordinated responses by followers on a risky action. In this context, we observe that women are equally effective as men at convincing followers to take more risk, regardless of whether followers know their gender. However, we also note that this paradigm, also employed by other researchers to investigate similar questions, may be a suboptimal instrument for detecting differences in persuasiveness between different groups of leaders.

The main motivation for our second experiment was to develop and use a more powerful paradigm for addressing our research question than the one in Experiment 1. In Experiment 2 we therefore introduce a different coordination game to study leadership effectiveness. In this game, two leaders give, at the same time, competing directives to followers. Followers simply want to coordinate on the same action in a simultaneous-move pure matching coordination game but are, otherwise, indifferent as to whose advice to follow. In this decision environment, even slight differences in the persuasiveness of female and male leaders should cause followers' behavior in the experiment to reveal a gender gap in leadership effectiveness. However, we again find no evidence in support of the hypothesis of differential effectiveness of male and female leaders. On the contrary, we estimate that female leaders who are in direct competition with a male leader are followed at an empirical rate very close to $50 \%$, regardless of whether their gender is known to followers. This is remarkable in light of the fact that the overall rate at which followers achieve coordination in the leader competition game is $59 \%$ when followers see messages and $64 \%$ when followers see messages and pictures, indicating that leader characteristics matter substantially. Both of these rates are statistically significantly different from the benchmark of a $50 \%$ equilibrium rate, at which followers would coordinate if leaders were not instrumental in equilibrium selection. In other words, while we find that the leader competition game is a useful instrument to measure leadership effectiveness, we find no evidence whatsoever that gender mediates differences in effectiveness.

We also document that this precisely estimated zero result is surprising to a set of research economists with expertise in the field of gender economics. DellaVigna and Pope (2018) find that the average forecast of expert researchers typically gets the level of an effect 
as well as the direction right. In contrast, we document that expert researchers anticipate a substantial gender gap in leader persuasiveness in our condition of Experiment 2 with visible leader photos, but that the actual data reveal no effect. In a recent paper on non-significant results in empirical economics Abadie (2020) makes a compelling argument that failures to reject a point null hypothesis should be given a much higher scientific significance by the intellectual community, particularly when these rejections are surprising. Given the expert predictions, our results are clearly surprising and change the prior beliefs held by the research community, including our own.

We hope that our results will contribute to updating widely held stereotypes on gender and leadership effectiveness. This is important, as mistaken beliefs may contribute to the low rate at which women are promoted into positions of leadership for which the ability to motivate and direct followers is key to good performance. In this case, it could take a long time for observational data to generate disconfirming evidence to correct such stereotypes. Relatedly, recent work by Bursztyn et al. (2020) finds direct evidence that mistaken beliefs-in their case about social norms regarding female labor supply-contribute to sustaining a gender gap in labor market outcomes.

Our results provide an indication that the source of the gender gap in top leadership positions cannot be justified by a general tendency for women to be inherently less persuasive and effective at directing coordinated action by followers. In our studies, there is nothing that women do that makes them less effective, and we find no evidence that a perception that they might be less effective yields self-confirming outcomes in which female leaders are less able to influence follower behavior. Of course, this does not mean that such equilibrium discrimination cannot happen outside the laboratory. Indeed, it might be more likely to occur in contexts where perceptions of competence and ability play a larger role than in our studies (see, e.g., Bohren et al. 2019), and where existing biases that women are less capable or knowledgeable might lead directives from female leaders to be less effective. In this regard, our study can be viewed as a useful starting point, demonstrating that a general perception of lower female leader efficacy alone cannot produce such effects.

\section{References}

Abadie, Alberto. 2020. “Statistical Nonsignificance in Empirical Economics.” American Economic Review: Insights 2 (2): 193-208. https://doi.org/10.1257/aeri.20190252. Bertrand, Marianne. 2020. "Gender in the Twenty-First Century." AEA Papers and Proceedings 110 (May): 1-24. https://doi.org/10.1257/pandp.20201126. 
Bertrand, Marianne, and Kevin F Hallock. 2001. "The Gender Gap in Top Corporate Jobs.” Industrial and Labor Relations Review 55 (1): 3-21. https://doi.org/10.2307/2696183.

Bhalotra, Sonia R., Irma Clots-Figueras, Lakshmi Iyer, and Joseph Vecci. 2018. "Leader Identity and Coordination.” SSRN Scholarly Paper ID 3253461. Rochester, NY: Social Science Research Network. https://papers.ssrn.com/abstract=3253461.

Blau, Francine D., and Lawrence M. Kahn. 2017. “The Gender Wage Gap: Extent, Trends, and Explanations.” Journal of Economic Literature 55 (3): 789-865. https://doi.org/10.1257/jel.20160995.

Bohren, J. Aislinn, Alex Imas, and Michael Rosenberg. 2019. "The Dynamics of Discrimination: Theory and Evidence.” American Economic Review 109 (10): 3395-3436. https://doi.org/10.1257/aer.20171829.

Bordalo, Pedro, Katherine Coffman, Nicola Gennaioli, and Andrei Shleifer. 2019. "Beliefs about Gender.” American Economic Review 109 (3): 739-73. https://doi.org/10.1257/aer.20170007.

Boring, Anne. 2017. “Gender Biases in Student Evaluations of Teaching.” Journal of Public Economics 145 (January): 27-41. https://doi.org/10.1016/j.jpubeco.2016.11.006.

Born, Andreas, Eva Ranehill, and Anna Sandberg. in press. “A Man’s World? The Impact of a Male Dominated Environment on Female Leadership.” Review of Economics and Statistics.

Brandts, Jordi, and David J. Cooper. 2006. "A Change Would Do You Good .... An Experimental Study on How to Overcome Coordination Failure in Organizations.” American Economic Review 96 (3): 669-93. https://doi.org/10.1257/aer.96.3.669.

— 2007. "It's What You Say, Not What You Pay: An Experimental Study of ManagerEmployee Relationships in Overcoming Coordination Failure.” Journal of the European Economic Association 5 (6): 1223-68. https://doi.org/10.1162/JEEA.2007.5.6.1223.

Brandts, Jordi, David J. Cooper, and Roberto A. Weber. 2015. "Legitimacy, Communication, and Leadership in the Turnaround Game.” Management Science 61 (11): 2627-45. https://doi.org/10.1287/mnsc.2014.2021.

Bursztyn, Leonardo, Alessandra L Gonzalez, and David Yanagizawa-Drott. in press. “Misperceived Social Norms: Women Working Outside the Home in Saudi Arabia." American Economic Review. 
Buser, Thomas, Muriel Niederle, and Hessel Oosterbeek. 2014. “Gender, Competitiveness, and Career Choices.” The Quarterly Journal of Economics 129 (3): 1409-47. https://doi.org/10.1093/qje/qju009.

Campa, Pamela, and Manuel Bagues. 2017. "Can Gender Quotas in Candidate Lists Empower Women? Evidence from a Regression Discontinuity Design.” 2017-06. Working Papers. Department of Economics, University of Calgary. https://ideas.repec.org/p/clg/wpaper/2017-06.html.

Carli, Linda L. 2017. “Social Influence and Gender.” In The Oxford Handbook of Social Influence, edited by Stephen G. Harkins, Kipling D. Williams, and Jerry Burger. Oxford University Press.

Chakraborty, Priyanka, and Danila Serra. 2019. “Gender Diferences in Top Leadership Roles: Does Worker Batter?” http://faculty.smu.edu/dserra/ChakrabortySerraLeadershipFeb2019.pdf.

Chattopadhyay, Raghabendra, and Esther Duflo. 2004. "Women as Policy Makers: Evidence from a Randomized Policy Experiment in India.” Econometrica 72 (5): 1409-43. https://doi.org/10.1111/j.1468-0262.2004.00539.x.

Cooper, David J., John R. Hamman, and Roberto A. Weber. in press. "Fool Me Once: An Experiment on Credibility and Leadership.” The Economic Journal. https://doi.org/10.1093/ej/ueaa059.

De Paola, Maria, Francesca Gioia, and Vincenzo Scoppa. 2018. “Teamwork, Leadership and Gender.” IZA Discussion Paper Series, no. 11861.

DellaVigna, Stefano, and Devin Pope. 2018. "Predicting Experimental Results: Who Knows What?” Journal of Political Economy $126 \quad$ (6): 2410-56. https://doi.org/10.1086/699976.

DellaVigna, Stefano, Devin Pope, and Eva Vivalt. 2019. "Predict Science to Improve Science.” Science 366 (6464): 428-29. https://doi.org/10.1126/science.aaz1704.

Dionne, Shelley D, Francis J Yammarino, Leanne E Atwater, and William D Spangler. 2004. “Transformational Leadership and Team Performance." Journal of Organizational Change Management $17 \quad$ (2): $177-93$. https://doi.org/10.1108/09534810410530601.

Eagly, Alice H., and Steven J. Karau. 2002. “Role Congruity Theory of Prejudice toward Female Leaders.” Psychological Review $109 \quad$ (3): 573-98. https://doi.org/10.1037//0033-295X.109.3.573. 
Eagly, Alice H., Steven J. Karau, and Mona G. Makhijani. 1995. "Gender and the Effectiveness of Leaders: A Meta-Analysis.” Psychological Bulletin 117 (1): 12545. https://doi.org/10.1037/0033-2909.117.1.125.

Eckbo, B. Espen, Knut Nygaard, and Karin S. Thorburn. 2016. "How Costly Is Forced Gender-Balancing of Corporate Boards?” SSRN Scholarly Paper ID 2746786. Rochester, NY: Social Science Research Network. https://papers.ssrn.com/abstract=2746786.

Fischbacher, Urs. 2007. “Z-Tree: Zurich Toolbox for Ready-Made Economic Experiments.” Experimental Economics 10 (2): 171-78. https://doi.org/10.1007/s10683-006-91594.

Foss, Nicolai. 2001. "Leadership, Beliefs and Coordination: An Explorative Discussion.” Industrial and Corporate Change 10 (2): 357-88.

Fuller, Joseph, Stephen Hansen, Tejas Ramdas, and Raffaella Sadun. 2020. “The Changing Nature of the C-Suite Job: Evidence from Job Descriptions.” https://conference.nber.org/conf_papers/f141826.slides.pdf.

Gangadharan, Lata, Tarun Jain, Pushkar Maitra, and Joseph Vecci. 2016. “Social Identity and Governance: The Behavioral Response to Female Leaders.” European $\begin{array}{llll}\text { Economic } & \text { Review } & 90 & \text { 302-25. }\end{array}$ https://doi.org/10.1016/j.euroecorev.2016.01.003.

Gipson, Asha N., Danielle L. Pfaff, David B. Mendelsohn, Lauren T. Catenacci, and W. Warner Burke. 2017. "Women and Leadership: Selection, Development, Leadership Style, and Performance.” The Journal of Applied Behavioral Science 53 (1): 32-65. https://doi.org/10.1177/0021886316687247.

Gloor, Jamie L., Manuela Morf, Samantha Paustian-Underdahl, and Uschi Backes-Gellner. 2020. "Fix the Game, Not the Dame: Restoring Equity in Leadership Evaluations." Journal of Business Ethics 161 (3): 497-511. https://doi.org/10.1007/s10551-0183861-y.

Gobillon, Laurent, Dominique Meurs, and Sébastien Roux. 2015. "Estimating Gender Differences in Access to Jobs.” Journal of Labor Economics 33 (2): 317-63. https://doi.org/10.1086/678495.

Goldin, Claudia, and Cecilia Rouse. 2000. "Orchestrating Impartiality: The Impact of ‘Blind’ Auditions on Female Musicians.” American Economic Review 90 (4): 71541. https://doi.org/10.1257/aer.90.4.715. 
Greenwald, A. G., D. E. McGhee, and J. L. Schwartz. 1998. "Measuring Individual Differences in Implicit Cognition: The Implicit Association Test.” Journal of Personality and Social Psychology 74 (6): 1464-80.

Greenwald, Anthony G., Brian A. Nosek, and Mahzarin R. Banaji. 2003. "Understanding and Using the Implicit Association Test: I. An Improved Scoring Algorithm.” Journal of Personality and Social Psychology 85 (2): 197-216. https://doi.org/10.1037/0022-3514.85.2.197.

Grossman, Philip J., Catherine Eckel, Mana Komai, and Wei Zhan. 2019. “It Pays to Be a Man: Rewards for Leaders in a Coordination Game.” Journal of Economic Behavior \& Organization 161 (May): 197-215. https://doi.org/10.1016/j.jebo.2019.04.002.

Grossman, Philip J., Mana Komai, and James E. Jensen. 2015. “Leadership and gender in groups: An experiment.” Canadian Journal of Economics/Revue canadienne d'économique 48 (1): 368-88. https://doi.org/10.1111/caje.12123.

Grunspan, Daniel Z., Sarah L. Eddy, Sara E. Brownell, Benjamin L. Wiggins, Alison J. Crowe, and Steven M. Goodreau. 2016. "Males Under-Estimate Academic Performance of Their Female Peers in Undergraduate Biology Classrooms.” PLOS ONE 11 (2): e0148405. https://doi.org/10.1371/journal.pone.0148405.

Kleven, Henrik, Camille Landais, and Jakob Egholt Søgaard. 2019. “Children and Gender Inequality: Evidence from Denmark.” American Economic Journal: Applied Economics 11 (4): 181-209. https://doi.org/10.1257/app.20180010.

Koenig, Anne M., Alice H. Eagly, Abigail A. Mitchell, and Tiina Ristikari. 2011. “Are Leader Stereotypes Masculine? A Meta-Analysis of Three Research Paradigms.” Psychological Bulletin 137 (4): 616-42. https://doi.org/10.1037/a0023557.

Kotter, John P. 2001. "What Leaders Really Do.” Harvard Business Review, 2001. https://hbr.org/2001/12/what-leaders-really-do.

Matsa, David A, and Amalia R Miller. 2013. “A Female Style in Corporate Leadership? Evidence from Quotas.” American Economic Journal: Applied Economics 5 (3): 136-69. https://doi.org/10.1257/app.5.3.136.

Mengel, Friederike, Jan Sauermann, and Ulf Zölitz. 2019. "Gender Bias in Teaching Evaluations.” Journal of the European Economic Association 17 (2): 535-66. https://doi.org/10.1093/jeea/jvx057.

Northouse, Peter G. 2012. Leadership: Theory and Practice. 6th ed. Los Angeles: Sage publications. 
Paustian-Underdahl, Samantha C., Lisa Slattery Walker, and David J. Woehr. 2014. "Gender and Perceptions of Leadership Effectiveness: A Meta-Analysis of Contextual Moderators.” Journal of Applied Psychology 99 (6): 1129-45. https://doi.org/10.1037/a0036751.

Preece, Jessica, and Olga Stoddard. 2015. "Why Women Don’t Run: Experimental Evidence on Gender Differences in Political Competition Aversion.” Journal of Economic Behavior \& Organization 117 (C): 296-308.

Reuben, Ernesto, and Krisztina Timko. 2018. “On the Effectiveness of Elected Male and Female Leaders and Team Coordination.” Journal of the Economic Science Association 4 (2): 123-35. https://doi.org/10.1007/s40881-018-0056-3.

Ridgeway, Cecilia L. 2001. “Gender, Status, and Leadership.” Journal of Social Issues 57 (4): 637-55. https://doi.org/10.1111/0022-4537.00233.

Rudman, Laurie A., and Peter Glick. 2001. "Prescriptive Gender Stereotypes and Backlash Toward Agentic Women.” Journal of Social Issues 57 (4): 743-62. https://doi.org/10.1111/0022-4537.00239.

Rudman, Laurie A., and Stephen E. Kilianski. 2000. "Implicit and Explicit Attitudes Toward Female Authority.” Personality and Social Psychology Bulletin 26 (11): 1315-28. https://doi.org/10.1177/0146167200263001.

Rudman, Laurie, and Stephen Kilianski. 2000. "Implicit and Explicit Attitudes Toward Female Authority.” Personality and Social Psychology Bulletin 26 (November): 1315-28. https://doi.org/10.1177/0146167200263001.

Sarsons, Heather, Klarita Gërxhani, Ernesto Reuben, and Arthur Schram. in press. "Gender Differences in Recognition for Group Work.” Journal of Political Economy.

Schelling, Thomas C. 1969. "Models of Segregation.” The American Economic Review 59 (2): 488-93.

Shurchkov, Olga, and Alexandra V. M. van Geen. 2019. "Why Female Decision-Makers Shy Away from Promoting Competition.” Kyklos 72 (2): 297-331. https://doi.org/10.1111/kykl.12202.

Timko, Krisztina. 2017. "The Selection Process and Not Gender Matters for Effective Leadership.” $\quad P h D$ Thesis University of Helsinki. https://pdfs.semanticscholar.org/421e/47a2b078f97d9bdc5b279701cb513cfae51a.p df. 
Van Huyck, John B., Raymond C. Battalio, and Richard O. Beil. 1990. “Tacit Coordination Games, Strategic Uncertainty, and Coordination Failure.” The American Economic Review 80 (1): 234-48.

Weber, Roberto, Colin Camerer, Yuval Rottenstreich, and Marc Knez. 2001. “The Illusion of Leadership: Misattribution of Cause in Coordination Games.” Organization Science 12 (5): 582-98. https://doi.org/10.1287/orsc.12.5.582.10090. 


\section{Appendix A - Additional analysis}

The Appendix contains the following additional figures:

- Experiments 1 and 2: Empirical Distribution of IAT Scores in Sample of Followers

- Experiment 1 and 2: Histograms of GAM Scores in Sample of Followers

- Experiment 1: Distribution of Group Outcomes in Period 7 by Condition

- Experiment 2: Follower Decision Screen in Leader Competition Game

- $\quad$ Experiment 2: Power Curve for Experiment 2

The Appendix contains the following additional tables

- Experiment 1: Employee and CEO Payoffs in Parts 1 and 2

- Experiment 1: Average Minimum Hours Invested in Part 1 by Condition

- Experiment 1: results of OLS regressions that test whether gender of the follower mediates the response to female leadership

- Experiment 1: A table with the categories into which messages were coded and summary statistics

- Experiment 2: Follower Behavior in Response to the Same Leader Pair in a Round by Gender-Visibility

- Experiment 2: results of an OLS regression predicting the probability that a leader is followed as a function of treatment indicators and control variables 
Figure A1. Empirical Distribution of IAT Scores in Sample of Followers (Experiments 1 and 2)

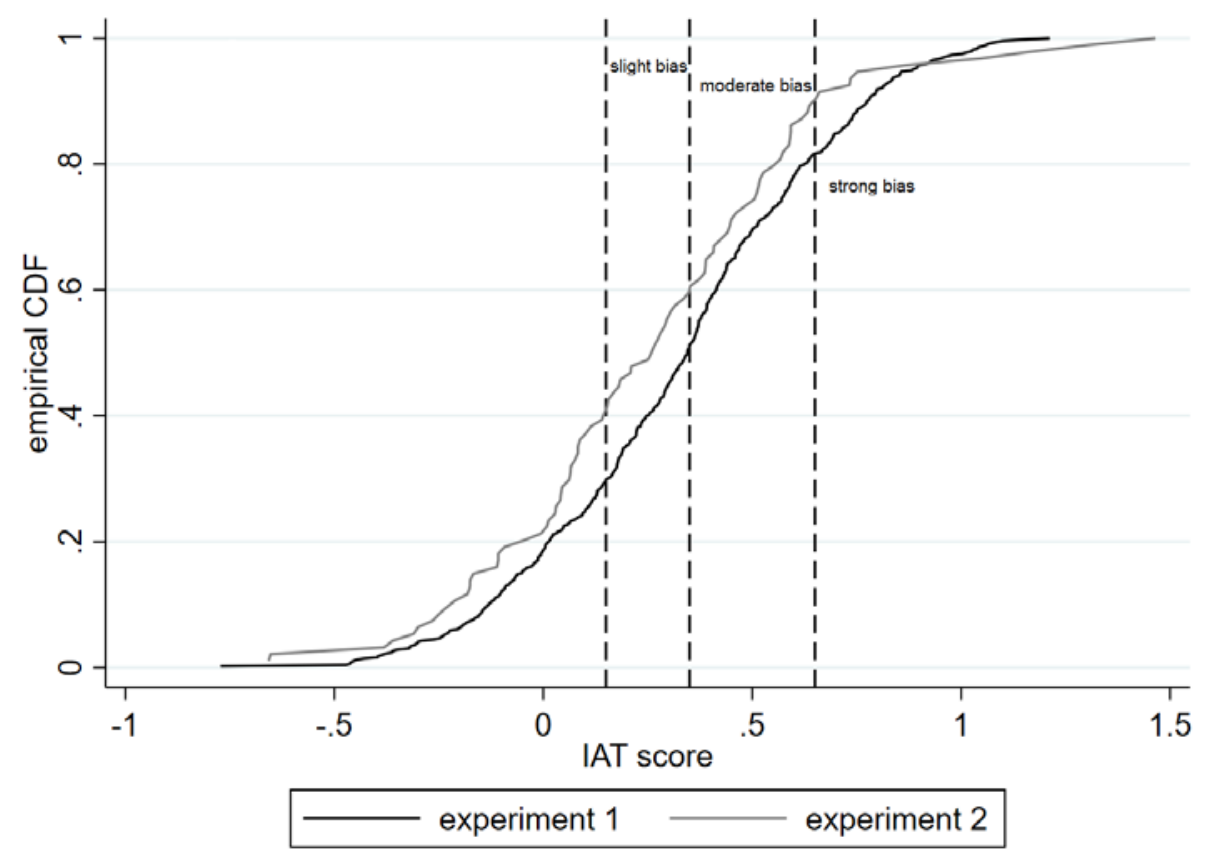

Notes: The IAT measures the implicit tendency to associate leadership more strongly with men than with women. It ranges from -2 to 2 and positive numbers above 0.15 mean that a subject is biased in associating leadership more strongly with men than with women. The higher the number, the stronger the bias, with values above 0.35 indicating a modest bias and numbers above 0.65 indicating a strong bias in favor of men.

Figure A2. Histograms of GAM scores (Experiments 1 and 2)

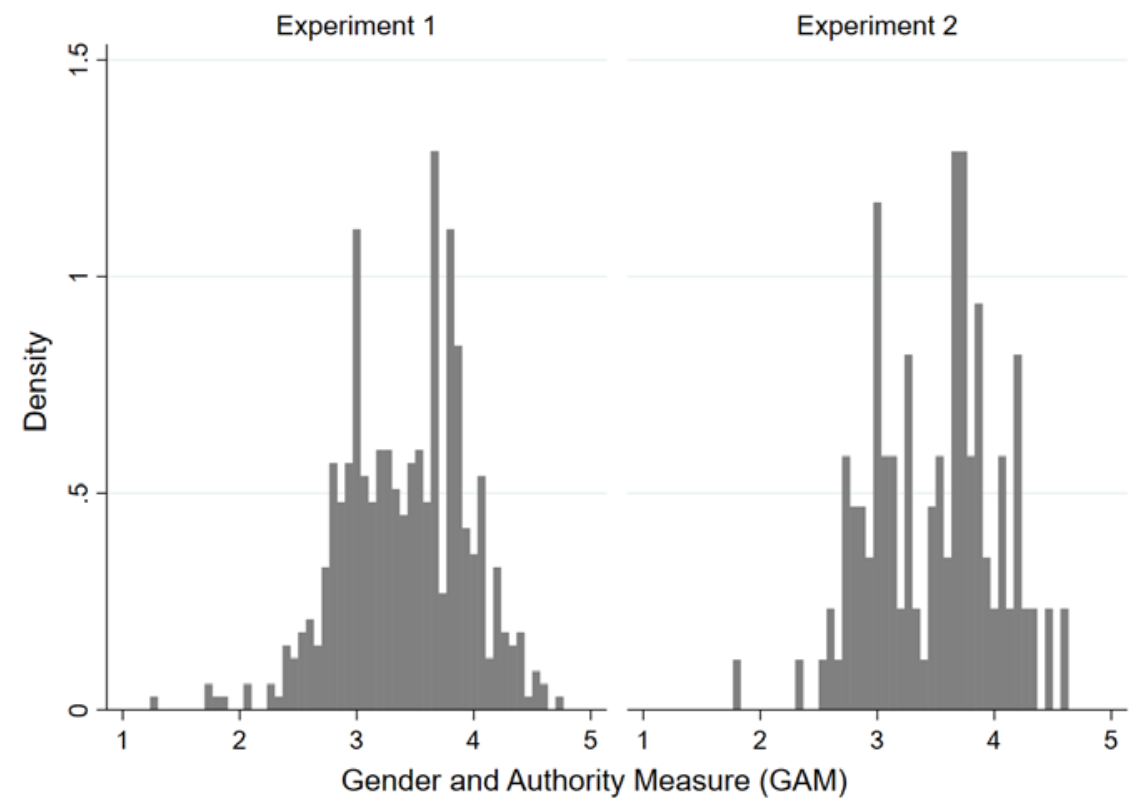

Notes: The GAM ranges from 1-5 and measures an explicit preference for male versus female authorities. Scores above 3 indicate a preference in this direction, with higher scores indicating a stronger preference. 
Figure A3. Distribution of Group Outcomes in Period 7 by Condition (Experiment 1)

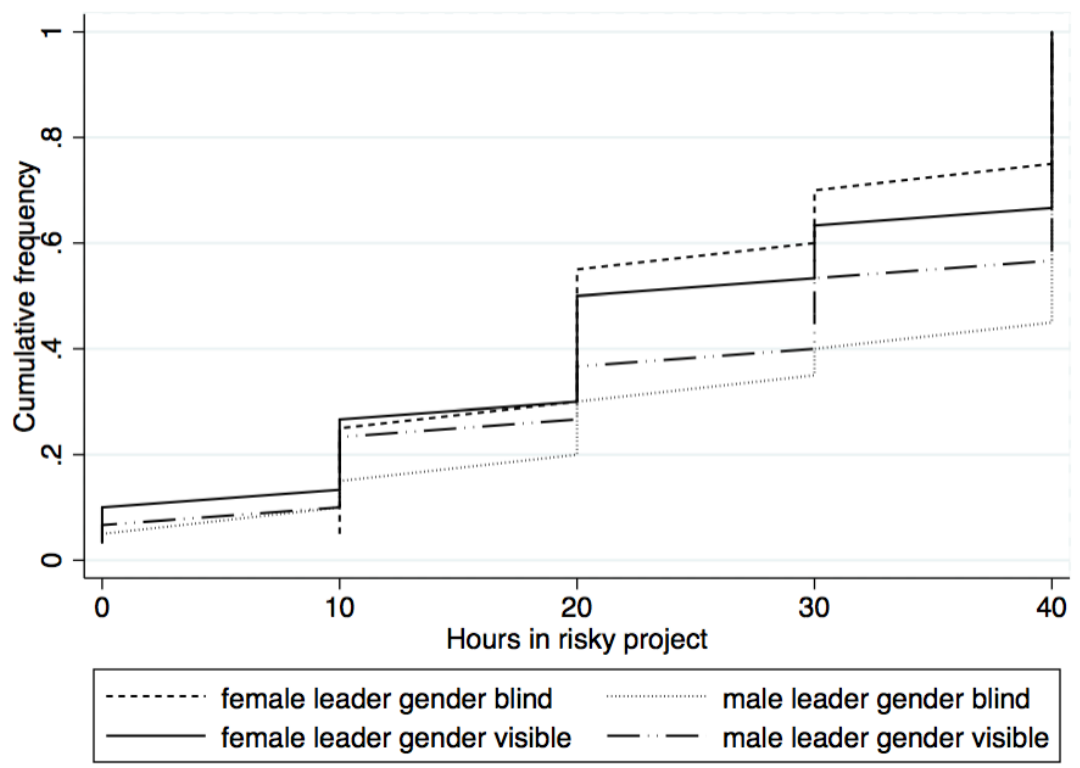


Figure A4. Decision Screen Investors Leader Competition Game

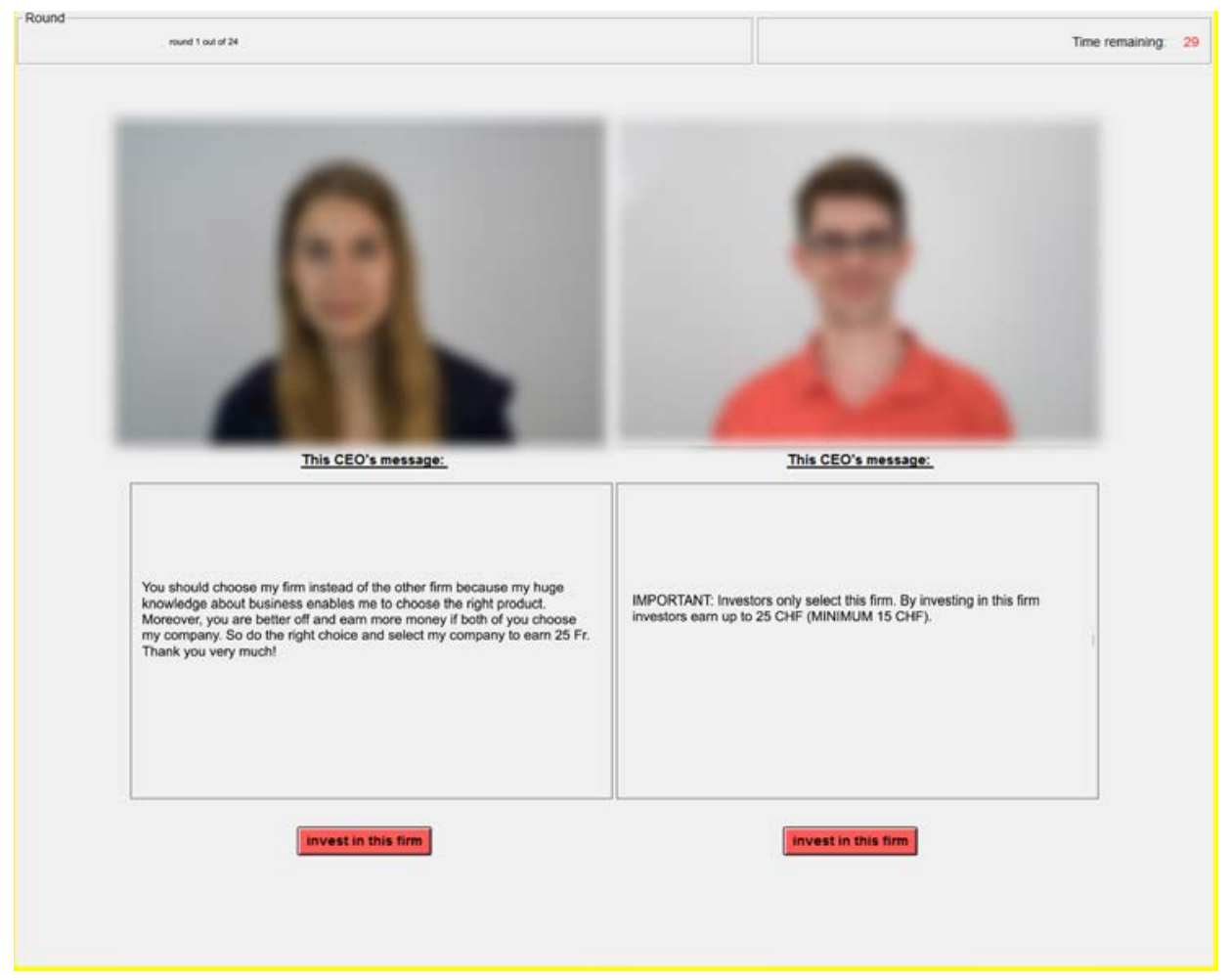

Notes: Faces of participants are blurred here to preserve their anonymity. Whenever pictures were displayed to participants in the experiment, they were not blurred.

\section{Figure A5. Power Curve for Experiment 2}

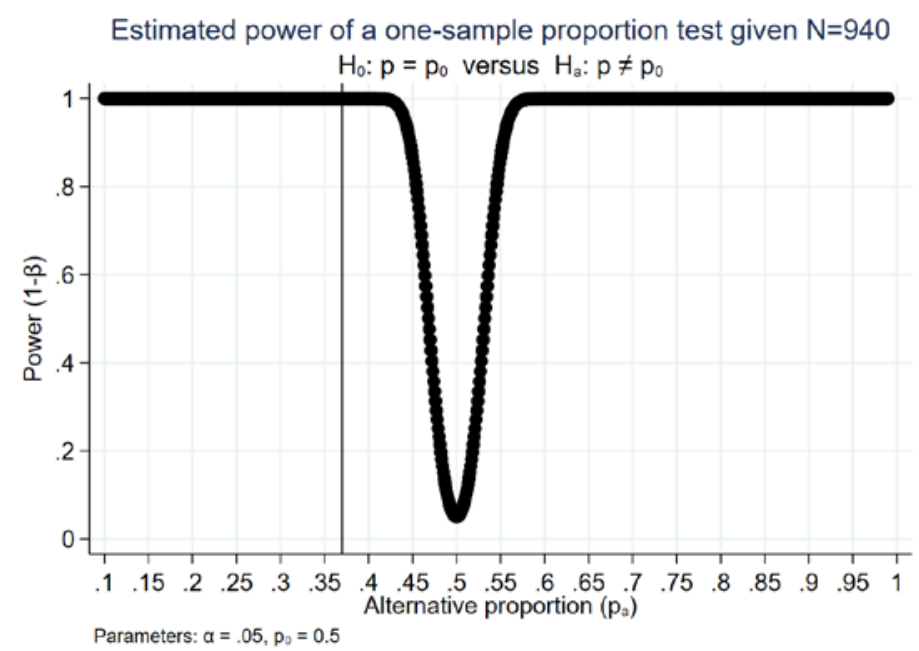

Notes: Figure depicts the power of our study, using a two-sided one-sample test of proportion to reject the null hypothesis that women are followed at the same rate as men, that is, at a rate of $50 \%$, at the 0.05 level of statistical significance or higher. The power is plotted as a function of alternative hypotheses, that is, alternative proportions at which women could be followed in the leader competition game whenever they are pitted against a male leader. The reference line is at the average rate of female following that the sample of research economists predicted for the gender visible condition. 
Table A1. Employee and CEO Payoffs in Parts 1 and 2 (Experiment 1)

Part 1 (Periods 1-6)

\begin{tabular}{|c|c|c|c|c|c|c|c|c|c|c|}
\hline \multirow{2}{*}{$\begin{array}{l}\text { Hours spent } \\
\text { on the risky } \\
\text { project }\end{array}$} & \multicolumn{5}{|c|}{$\begin{array}{l}\text { Minimum hours spent by others on the } \\
\text { risky project }\end{array}$} & \multicolumn{5}{|c|}{$\begin{array}{l}\text { Minimum hours spent by others on the } \\
\text { risky project }\end{array}$} \\
\hline & 0 & 10 & 20 & 30 & 40 & 0 & 10 & 20 & 30 & 40 \\
\hline 0 & 200 & 200 & 200 & 200 & 200 & 200 & 200 & 200 & 200 & 200 \\
\hline 10 & 150 & 200 & 200 & 200 & 200 & 150 & 210 & 210 & 210 & 210 \\
\hline 20 & 100 & 150 & 200 & 200 & 200 & 100 & 160 & 220 & 220 & 220 \\
\hline 30 & 50 & 100 & 150 & 200 & 200 & 50 & 110 & 170 & 230 & 230 \\
\hline 40 & 0 & 50 & 100 & 150 & 200 & 0 & 60 & 120 & 180 & 240 \\
\hline CEO Payoff & \multicolumn{10}{|c|}{ average earnings of employees in same firm } \\
\hline & \multicolumn{5}{|c|}{ Rate of return $=5$} & \multicolumn{5}{|c|}{ Rate of return $=6$} \\
\hline
\end{tabular}

Part 2 (Periods 7-16)

\begin{tabular}{|c|c|c|c|c|c|c|c|c|c|c|}
\hline \multirow{2}{*}{$\begin{array}{l}\text { Hours spent } \\
\text { on the risky } \\
\text { project }\end{array}$} & \multicolumn{5}{|c|}{$\begin{array}{l}\text { Minimum hours spent by others on the } \\
\text { risky project }\end{array}$} & \multicolumn{5}{|c|}{$\begin{array}{l}\text { Minimum hours spent by others on the } \\
\text { risky project }\end{array}$} \\
\hline & 0 & 10 & 20 & 30 & 40 & 0 & 10 & 20 & 30 & 40 \\
\hline 0 & 200 & 200 & 200 & 200 & 200 & 200 & 200 & 200 & 200 & 200 \\
\hline 10 & 150 & 230 & 230 & 230 & 230 & 150 & 250 & 250 & 250 & 250 \\
\hline 20 & 100 & 180 & 260 & 260 & 260 & 100 & 200 & 300 & 300 & 300 \\
\hline 30 & 50 & 130 & 210 & 290 & 290 & 50 & 150 & 250 & 350 & 350 \\
\hline \multirow[t]{3}{*}{40} & 0 & 80 & 160 & 240 & 320 & 0 & 100 & 200 & 300 & 400 \\
\hline & \multicolumn{10}{|c|}{ Minimum hours spent on the risky project in firm } \\
\hline & 0 & 10 & 20 & 30 & 40 & 0 & 10 & 20 & 30 & 40 \\
\hline \multirow[t]{2}{*}{ CEO Payoff } & 150 & 230 & 310 & 390 & 470 & 150 & 250 & 350 & 450 & 550 \\
\hline & \multicolumn{5}{|c|}{ Rate of return $=8$} & \multicolumn{5}{|c|}{ Rate of return $=10$} \\
\hline
\end{tabular}


Table A2. Average Minimum Hours Invested in Part 1 by Condition (Experiment 1)

\begin{tabular}{lcc}
\hline Condition & Rounds 1-6 & Round 6 \\
\hline Female leader gender unknown & $2.17(4.63)$ & $1.50(3.66)$ \\
Female leader gender known & $4.5(6.95)$ & $3.67(6.69)$ \\
Male leader gender unknown & $2.67(4.62)$ & $2.00(4.10)$ \\
Male leader gender known & $0.89(2.85)$ & $0.33(1.83)$ \\
\hline p-value (Kruskal-Wallis) & $\mathrm{p}=0.177$ & $\mathrm{p}=0.083$ \\
\hline
\end{tabular}

Notes: Standard deviation in parentheses.

Table A3. Impact of Gender Leader on Followers' Initial Individual Investments (Experiment 1)

\begin{tabular}{|c|c|c|c|c|}
\hline & \multicolumn{4}{|c|}{ Hours invested in risky project by follower i } \\
\hline & Period 7 & Period 7 & Period 7 & Period 7 \\
\hline Female Leader & $\begin{array}{r}-3.669 \\
(2.366)\end{array}$ & $\begin{array}{r}0.944 \\
(1.259)\end{array}$ & $\begin{array}{l}-3.795 \\
(2.305)\end{array}$ & $\begin{array}{r}-4.152 \\
(2.889)\end{array}$ \\
\hline Leader Visibility & $\begin{array}{r}-2.852 \\
(2.310)\end{array}$ & $\begin{array}{r}-0.670 \\
(1.001)\end{array}$ & $\begin{aligned}-4.559^{* *} \\
(2.305)\end{aligned}$ & $\begin{array}{r}-1.340 \\
(2.754)\end{array}$ \\
\hline $\begin{array}{l}\text { Female Leader X Leader } \\
\text { Visibility }\end{array}$ & $\begin{array}{r}2.814 \\
(3.259)\end{array}$ & $\begin{array}{r}-0.335 \\
(1.920)\end{array}$ & $\begin{array}{r}4.951 \\
(3.259)\end{array}$ & $\begin{array}{r}1.190 \\
(3.887)\end{array}$ \\
\hline Group Performance Part 1 & $\begin{array}{r}0.263 \\
(0.105)\end{array}$ & $\begin{array}{r}0.009 \\
(0.056)\end{array}$ & $\begin{array}{r}0.142 \\
(0.109)\end{array}$ & $\begin{array}{r}0.407 \\
(0.134)\end{array}$ \\
\hline $\begin{array}{l}\text { Leader Recommendation } \\
\text { (number of hours) }\end{array}$ & & $\begin{array}{r}0.710^{* * *} \\
(0.082)\end{array}$ & & \\
\hline Constant & $\begin{array}{r}35.743^{* * *} \\
(1.581)\end{array}$ & $\begin{array}{r}9.913 \\
(3.295)\end{array}$ & $\begin{array}{r}37.112^{* * *} \\
(1.413)\end{array}$ & $\begin{array}{r}34.590^{* * *} \\
(2.063)\end{array}$ \\
\hline \multirow[t]{2}{*}{$\mathrm{N}$ followers } & 500 & 410 & 254 & 246 \\
\hline & & & $\begin{array}{c}\text { male } \\
\text { followers only }\end{array}$ & $\begin{array}{c}\text { female } \\
\text { followers only }\end{array}$ \\
\hline$R^{2}$ & 0.0322 & 0.549 & 0.0319 & 0.0492 \\
\hline
\end{tabular}

Notes: Female leader is an indicator for whether the leader 1 of a group is female and leader visibility indicates whether the portrait was shown to followers. Female leader $X$ leader visibility interacts these two terms. Group performance in Part 1 is the highest group equilibrium played - the maximum of the minimum hours a group invested in the risky project - over the last three periods of Part 1. Leader recommendation (number of hours) records the specific numeric investment recommendation the leader gave to followers, whenever such a specific request was made. Standard errors in parentheses (clustered at the group level). *Significant at the $10 \%$ level, ${ }^{* *}$ at the $5 \%$ level, *** at the $1 \%$ level. 
Table A4. Message Categories and Corresponding Frequencies (Experiment 1)

\begin{tabular}{|c|c|c|c|c|c|c|}
\hline \multicolumn{2}{|r|}{ Category and Description } & \multicolumn{2}{|c|}{ Overall Frequency } & \multicolumn{2}{|c|}{$\begin{array}{c}\text { Frequency in period } \\
7\end{array}$} & \multirow[t]{2}{*}{$\kappa$} \\
\hline & & Men & Women & Men & Women & \\
\hline $1 \mathrm{a}$ & Suggested effort level 0 & 0.004 & 0.004 & 0.02 & 0.02 & 0.7996 \\
\hline $1 \mathrm{~b}$ & Suggested effort level 10 & 0.014 & 0.032 & 0.04 & 0.06 & 0.9029 \\
\hline 1c & Suggested effort level 20 & $0.018 * * *$ & $0.054 * * *$ & 0.06 & 0.12 & 0.8990 \\
\hline $1 d$ & Suggested effort level 30 & $0.032 * * *$ & $0.088 * * *$ & 0.06 & 0.06 & 0.8920 \\
\hline 1e & Suggested effort level 40 & $0.51 * *$ & $0.444^{* *}$ & $0.72 * *$ & $0.52 * *$ & 0.7516 \\
\hline 1f & $\begin{array}{l}\text { Ambiguous suggestion, } \\
\text { positive but not specific }\end{array}$ & $0.106 * * *$ & $0.180 * * *$ & $0.08 * *$ & $0.24 * *$ & 0.4298 \\
\hline 2 & $\begin{array}{l}\text { Explanation for suggested } \\
\text { effort }\end{array}$ & $0.243^{* *}$ & $0.185^{* *}$ & $0.86^{* * *}$ & $0.62 * * *$ & 0.5519 \\
\hline 3 & Appeals to mutual trust & 0.096 & 0.110 & 0.3 & 0.22 & 0.4021 \\
\hline 4 & Appeals to risk-seeking & 0.030 & 0.460 & 0.08 & 0.06 & 0.4099 \\
\hline 5 & $\begin{array}{l}\text { Positive feedback about } \\
\text { previous outcome }\end{array}$ & 0.575 & 0.544 & 0 & 0.04 & 0.7252 \\
\hline 6 & $\begin{array}{l}\text { Negative feedback about } \\
\text { previous outcome }\end{array}$ & $0.088 * * *$ & $0.302^{* * *}$ & 0 & 0 & 0.6543 \\
\hline 7 & $\begin{array}{l}\text { Message written in assertive } \\
\text { tone }\end{array}$ & $0.121^{* *}$ & $0.170^{* *}$ & 0.245 & 0.16 & 0.0555 \\
\hline 8 & $\begin{array}{l}\text { Message written in } \\
\text { supplicating tone }\end{array}$ & 0.048 & 0.044 & 0.10 & 0.16 & 0.1795 \\
\hline
\end{tabular}

Notes: The last column shows $\kappa$, a common measure of intercoder agreement. A $\kappa$ of 1 means perfect agreement and a value of 0 implies no more agreement than what would be expected by chance. Values between $0.41-0.60$ mean moderate agreement, values between $0.61-0.80$ indicate substantial agreement and values above 0.81 almost perfect agreement. Stars indicate the level of statistical significance of twosided tests of difference in proportions: $* *$ at the 0.05 level, *** at the 0.01 level of statistical significance.

Table A5. Follower Behavior in Response to the Same Leader Pair in a Round by Gender Visibility (Experiment 2)

\begin{tabular}{cc|c|c|c|} 
& \multirow{2}{*}{ Loth Choose M } & Both choose M & One F one M & Both choose F \\
\cline { 2 - 5 } Leader & $12.7 \%$ & 12.1 & 5.1 \\
\cline { 2 - 5 } invisible & One F one M & 13.0 & 13.6 & 13.2 \\
\cline { 2 - 5 } & Both Choose F & 6.0 & 11.7 & 12.6
\end{tabular}

Notes: The table displays the outcomes of follower behavior in response to the same leader pair of mixed gender by gender visibility. We observe the same 470 leader pairings once when their gender was visible to followers and once when it was not. Entries in the diagonal of that table represent instances in which the behavior of followers was the same, irrespective of whether the gender of the leaders was known. Cells shaded in light gray indicate instances in which gender-visibility brought about a more female following. White cells indicate instances in which followers followed the male leader more, when the gender of the two leaders was visible. 
Table A6. Estimates of OLS Regression Predicting A Leader Being Followed

Female leader ( $i)$

$-0.0544$

$(0.0380)$

Picture

$-0.0119$

(0.0299)

Female leader x Picture

Female follower $(j)$

Female follower x Female leader

0.0367

$-0.0776$

(0.0643)

Message length

$0.311^{* * *}$

(fraction of longest message)

Left screen position

$-0.00347$

(0.0159)

0.0162

(0.0302)

$0.319 * * *$

(0.0433)

3760

0.032

Adjusted $R^{2}$

Notes: The dependent variable equals 1 if the leader's recommendation is followed and 0 otherwise. Female leader indicates that a leader is a woman, picture indicates that the leader's picture was visible to followers, female leader $X$ picture interacts these two terms. Female follower indicates that the follower is a woman. Message length is a variable that records the character length of the leader's message as a fraction of the message with the most characters in the sample. Left screen position indicates that the leader's message was randomly displayed on the left side of the screen. Native English speaker indicates that the leader is a native English speaker. Standard errors in parentheses (clustered at the leader level). *Significant at the $10 \%$ level, ${ }^{* *}$ at the $5 \%$ level, ${ }^{* * *}$ at the $1 \%$ level. 


\section{Appendix B1. Leader Persuasiveness in Coordination Games}

In our first experiment, we model leadership as the ability to persuade all followers to collectively change behavior and move from an investment level of zero units to a recommended positive amount invested in the risky project. Successful leaders can influence equilibrium selection in this coordination game. In the following paragraphs, we introduce a simple theoretical framework that captures how leaders mediate equilibrium selection in one-shot simultaneous move coordination games through an individual trait that we refer to as "leader persuasiveness." This notion is applied to two types of coordination games. The analysis provides insights into why we designed and implemented a second experiment.

\subsection{Weak-Link Game}

The first coordination game that we consider is a simplified version of the weak-link game of Experiment 1. In its simplest representation, the weak-link game is the following version of a Stag Hunt coordination game. Followers $i \in\{1,2,3, \ldots, n\}$ with $n \geq 2$ choose simultaneously between two actions. They can either invest a positive amount in a group project, $I_{G}=1$, or not invest, $I_{G}=0$. Followers all have the same payoff function. They receive some guaranteed amount $\pi_{0}>0$ when they do not invest in the group project $\left(I_{G}=\right.$ $0)$. This amount is independent of the action of other followers. When they choose to invest $\left(I_{G}=1\right)$ in the group project, followers receive a payoff equal to $\pi_{G}$ whenever all others invest, and 0 otherwise, with $\pi_{G}>\pi_{0}$. Figure B1 illustrates the payoff table for followers for the case of two players.

Before all followers make their choice, a leader $l$ can send a written statement $r_{l}$ to all followers, in which she advises the followers on whether to invest in the group project. All followers read $r_{l}$ before they simultaneously decide whether to invest in the group project, and that is common knowledge. The leader receives a payoff equal to $\pi_{G}$ when all followers invest in the group project and receives a payoff of 0 otherwise.

This game has two pure-strategy equilibria in which all followers choose the same action. From the perspective of the individual follower who decides on which strategy to play, the two strategies differ in the risk and return profiles.

\subsection{Leader Competition Game}

The design of Experiment 2 builds on a simple pure-matching coordination game. Followers $i \in\{1,2,3, \ldots, n\}$ with $n \geq 2$ choose simultaneously between two actions. They 
can either play action $F$ or action $M$. Followers receive a payoff of $\pi_{C}>0$ when they all play the same action, which can be either $F$ or $M$, and a payoff of 0 if their actions do not match. See Figure B1 for an illustration of follower payoffs for the case of two players. Before all followers make their choice, two leaders $l^{1}, l^{2}$ can each send a written statement $r_{l^{1}}, r_{l^{2}}$. In the statement, a leader advises the followers on which action they should play. All followers read the two statements $r_{l^{1}}, r_{l^{2}}$ before they simultaneously decide whether to play $F$ or $M$, and that is common knowledge. One leader is a woman and the other leader is a man. The leaders have opposing preferences. The female leader obtains a payoff of $\pi_{C}>$ 0 when all followers choose action $F$ and a payoff of 0 otherwise. The male leader obtains a payoff of $\pi_{C}>0$ when all followers choose action $M$ and, otherwise, a payoff of 0 .

The second-stage game between the followers has two pure-strategy equilibria in which all followers choose the same action, as well as mixed-strategy equilibria involving randomization. From the perspective of the individual follower who decides on which strategy to play, the two strategies are equivalent in terms of their risk and return profiles.

\section{Figure B1. Follower Payoffs in the Weak-Link Game and the Leader-Competition Game when $\mathrm{N}=2$}
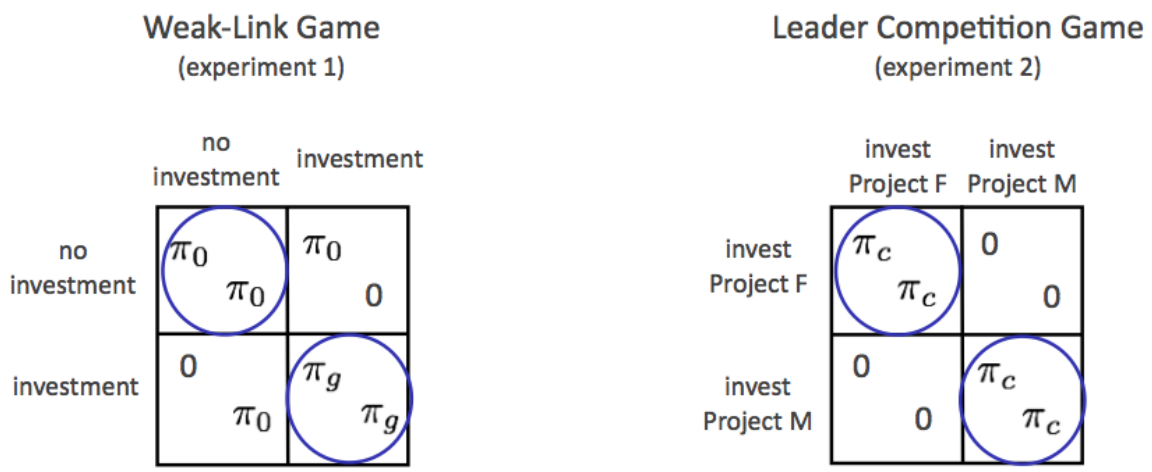

Notes: Blue circled cells indicate that the outcome is a pure-strategy Nash Equilibrium.

\subsection{Leader Persuasiveness and Leader Social Credibility}

We posit that the followers' perception of leadership quality is instrumental in selecting the equilibrium that followers will play.

Definition 1. A leader's persuasiveness $\alpha(r, k) \in[0,1]$ is a follower's subjective perception of the degree to which the leader's statement is convincing

The leader's persuasiveness is a function of the statement $r$ that the leader writes to convince followers to play a specific strategy in a coordination game. Moreover, we conceptualize that the leader's persuasiveness may also be a function of observable leader 
characteristics $k$, for example, the leader's gender, ethnicity, height, eye color, voice tone. Gender is the leader characteristic that randomly varies in the modeled experiments and because of this, we use $k \in\{f, m\}$ as a summary of all relevant leader characteristics. In our leader-blind conditions, we eliminate the possibility that $k$ influences persuasiveness, meaning that any gender difference must come from differences in male and female leaders' distributions of message quality, $r$. The gender-visible conditions, on the other hand, allow for differences in persuasiveness to arise solely because of different leader characteristics, $k$.

In simultaneous move coordination games, a follower wants to take the action that she believes others are likely to take because of the strong complementarity in actions. Because of this, a follower forms a belief $p \in[0,1]$ about how likely it is that all others are going to take the advice of a leader instead of ignoring it. We conceptualize a leader's "social credibility,” $p(\alpha)$, as the subjective probability that a follower assigns to all others in the group playing the equilibrium that is promoted by the leader. ${ }^{27}$

Definition 2. A leader's social credibility $p(\alpha) \in[0,1]$ is the follower's prior belief about how likely it is that all others in the group will be convinced by the leader's advice instead of ignoring it.

We conceptualize that this prior belief $p(\alpha)$ is a function of leader's persuasiveness $\alpha(r, k) \in[0,1]$. It is specific to either type of game and we make minimal and plausible assumptions about how a leader's persuasiveness $\alpha(r, k)$ maps into the leader's social credibility $p(\alpha) .^{28}$

Assumption 1 (A1) In the Weak-Link Game, $p(0)=0, p(1)=1$ and $p^{\prime}(\alpha)>0$, in other words, $p($ ) is strictly monotonically increasing in $\alpha$.

\footnotetext{
${ }^{27}$ It is common to advance prior beliefs about the relative likelihood of equilibria in theories of equilibrium selection. Harsanyi and Selten (1988), for example, conceptualize that players of a game understand that the outcome of the game will be a Nash equilibrium but that, initially, they do not know which one will be chosen, before they play the game. Through a specific way of reasoning about the relative likelihood that each equilibrium will be played, and player best-responding to these prior beliefs, the so called Harsanyi-Selten tracing procedure selects one equilibrium before the game is played.

${ }^{28}$ We impose that followers have a shared understanding of their leader's social credibility. This is a direct consequence of the modeling choice that all followers observe the same $\alpha(r, k)$. One way to justify it is that all followers read the same statement and that it seems plausible that followers have at least a similar view about the persuasiveness of that statement. For ease of exposition, instead of imposing some bounds on the degree to which the assessments $\alpha_{i}(r, k)$ may differ, we simply impose that $\alpha_{i}(r, k)=\alpha(r, k)$ for all followers $i$ in a group.
} 
This simply means that the subjective probability that a follower assigns to the others in her group following the advice of the leader, instead of ignoring it, increases, as the leader's statement is perceived to be more personally convincing.

In the Leader-Competition Game, the leaders’ social credibility is jointly determined, that is, each is a function of the persuasiveness of both leaders.

Assumption 2 (A2) In the Leader-Competition Game, $p_{1}\left(\alpha^{1}, \alpha^{2}\right)>p_{2}\left(\alpha^{1}, \alpha^{2}\right)$ with $p_{1}\left(\alpha^{1}, \alpha^{2}\right)+p_{2}\left(\alpha^{1}, \alpha^{2}\right)=1$ if $\alpha^{1}>\alpha^{2}$ and $p_{1}\left(\alpha^{1}, \alpha^{2}\right)=1-p_{2}\left(\alpha^{1}, \alpha^{2}\right)=$ 0.5 if $\alpha^{1}=\alpha^{2} \geq 0$.

In words, we assume that whenever a leader $\left(l^{1}\right)$ is more persuasive than the other leader $\left(l^{2}\right)$, a follower holds the prior belief that it is more likely that all others will choose the action promoted by $l^{1}$ than all playing the action promoted by $l^{2}$. Whenever the two leaders are exactly equally socially credible, a follower gives the same subjective probability to the two events that either all other followers will play $M$ or that all other followers will play $F$.

When followers ignore the advice of their leader, they play the "babbling equilibrium" of the coordination game. This situation is strategically equivalent to the second-stage coordination game played without a pre-play communication phase. This means that the equilibrium that followers play in the absence of leadership is the same as the babbling equilibrium of the game.

Assumption 3 (A3) When followers play the Weak-Link Game without the leader, followers play the equilibrium in which everyone invests zero units in the group project $\left(\boldsymbol{I}_{\boldsymbol{G}}^{*}=\mathbf{0}\right)$.

A3 reflects an important feature of the actual experimental context, in which groups converged to the play the risk-dominant equilibrium $\boldsymbol{I}_{\boldsymbol{G}}^{*}=\mathbf{0}$ in a first part of the experiment without a leader. Moreover, based on earlier research (e.g., Van Huyck, Battalio, and Beil, 1990; Brands and Cooper, 2006), it seems likely that groups will converge to the riskdominant but inefficient equilibrium in the absence of leadership in the weak-link game in our experiment.

Assumption 4 (A4) When followers play the Leader-Competition Game without the leader, the behavior of followers is best described by the mixed strategy Nash equilibrium $\boldsymbol{q}^{*}$ of the simple coordination game in which each follower randomizes between the play of $F$ and $M$ with equal probability, e.g. $q_{i}^{*}\left(\frac{1}{2}, \frac{1}{2}\right)$. 
Empirically, A4 must be satisfied in the aggregate; in anonymous experimental groups in which people interact once without communication they should coordinate around half of the time in this pure-matching coordination game. Nothing systematic can guide players' thinking in terms of which action is relatively more likely to be played by others.

Assumption 5 (A5) Followers either take the advice of the leader at face value or they ignore it.

A5 rules out that followers do, for example, collectively the opposite of what the leader says. Empirically, A5 is the most realistic way to think about followers' reaction to the messages in a one-shot simultaneous move game in which they cannot communicate. Theoretically, it is in line with the notion of focal points in coordination games that Schelling (1969) introduced to recognize that humans often have a way to single out specific actions as more salient than others.

Under A1-A5 we can compare the weak-link coordination game and the leader competition game in their ability to uncover that women are less effective leaders than men. In the framework that we introduced, the effectiveness of a leader is linked to the leader's social credibility.

For illustration, consider a scenario in which all women have the same persuasiveness $\alpha(r, f)$ and all men have the same persuasiveness $\alpha(r, m)$ which implies that all female leaders have the same leader social credibility $p\left(\alpha_{f}\right)$ and all men have the same leader social credibility $p\left(\alpha_{m}\right){ }^{29}$

The experimenter never directly observes the leader's social credibility or the underlying leader persuasiveness. The experimenter only observes followers' behavior, that is, the equilibrium they play. From this, outside observers can judge whether a leader was effective. In the weak-link game, an effective leader gets followers to invest in the risky project. In the leader competition game, the effective leader is the one who persuades followers to invest in the leader's preferred project. Our main interest is in how well each game performs in revealing differences in the social credibility of female and male leaders, given that outside observers only see the behavior of followers.

Proposition 1. Assume A1-A5.

29 The key insights of this modeling framework extend to a stochastic environment in which we assume that leader persuasiveness is distributed according to the cumulative distribution functions $F_{r, f}()$ and $F_{r, m}()$. Men are, stochastically, more persuasive than women if $F_{r, m}()$ if $F_{r, m}()$ first order stochastically dominates $F_{r, f}()$. 
- In the Weak-Link Game female leaders are less effective than male leaders if and only if $p(\alpha(r, f))<\frac{\pi_{0}}{\pi_{G}}<p(\alpha(r, m))$.

- In the Leader-Competition Game, female leaders are less effective than male leaders if and only if $\alpha(r, f)<\alpha(r, m)$.

Proof. See Appendix B2.

In the statement of Proposition 1, we do not differentiate between the cases in which differences in persuasiveness arise through differences in the quality of messages sent by male versus female leaders $(r)$ or followers' responses to leader characteristics $(k)$. Which one, if any, causes women's differential effectiveness as leaders is ultimately an empirical question that we are disentangling in our two experiments.

Proposition 1 implies that the weak-link game can fail to indicate any differences in the effectiveness of male and female leaders, even if men are (substantially) more socially credible than women (i.e., if $p(\alpha(r, m))$ and $p(\alpha(r, f))$ are both less than or greater than $\frac{\pi_{0}}{\pi_{G}}$, even if $|p(\alpha(r, m))-p(\alpha(r, f))|$ is large). In this game, all that is required in order for a follower to choose higher investment is that the follower believe it is sufficiently likely that others will do so. That is, there is a threshold belief about how likely others are to respond positively to a leader, and a belief below this threshold means that a follower should not increase her investment, while a higher belief means that the follower should. Thus, leaders are effective whenever their social credibility is above this threshold. It may be the case, therefore, that even when men and women differ in how credible they are believed to be, that they are both above or below the threshold, meaning that the weak-link game will not detect any differences in how effective men and women are to persuade others.

By contrast, Proposition 1 states that the leader competition game is guaranteed to show differences in leadership effectiveness whenever the statements of male leaders are perceived to be more persuasive than the statement by female leaders. This is the case because, in this game, any differences in the perceived persuasiveness will help followers to select which equilibrium to play. 


\section{Appendix B2 - Proofs}

Lemma 1. Assume A5. In the Weak-Link Game, the leader recommends $I_{G}=1$. In the Leader-Competition Game, the female leader recommends $F$ and the male leader recommends $M$.

Proof. This follows directly from A5 under which it is weakly better for a leader to recommend that followers choose actions that are weakly better for the leader

Lemma 2. Assume A1, A3, A5. A follower $i$ in the Weak-Link Game follows the advice of the leader if and only if $p(\alpha(r, k)) \geq \frac{\pi_{0}}{\pi_{G}}$.

Proof. Followers who ignore the advice of the leader play $I_{G}=0$ by A3. The leader recommends the play of $I_{G}=1$ by lemma 1 . By the definition of leader social credibility, a follower observes $(r, k)$ and assigns subjective probability $p(\alpha(\mathrm{r}, \mathrm{k}))$ to the event that all other followers will take the advice of the leader and assigns probability $1-p(\alpha(r, k))$ to the event that all other followers ignore it. Her unique best-response to prior belief $p(\alpha(\mathrm{r}, \mathrm{k}))$ is to ignore the advice and play $\mathrm{I}_{\mathrm{G}}=0$ when $p(\alpha(\mathrm{r}, \mathrm{k}))<\frac{\pi_{0}}{\pi_{\mathrm{G}}}$ and to take the advice of the leader and play $I_{G}=1$ when $(\alpha(r, k)) \geq \frac{\pi_{0}}{\pi_{G}}$. The primitives of the game are such that $\left.\frac{\pi_{0}}{\pi_{\mathrm{G}}} \in\right] 0,1[$. By A1, strict monotonicity of $p(\cdot)$ in $\alpha(r, k)$ and $p(0)=0, p(1)=1$ this threshold value $p(\alpha(r, k))=\frac{\pi_{0}}{\pi_{G}}$ is unique

Lemma 3. Assume A2, A4, A5. A follower $i$ in the Leader-Competition Game follows the advice of leader $l^{1}$ if and only if $\alpha^{1}(r, k)>\alpha^{2}(r, k) \geq 0$.

Proof. We will first show the if part of the proposition. By lemma 1, the two leaders recommend different actions. Label the strategy that leader $l^{1}$ promotes $L^{1} \in\{\mathrm{F}, \mathrm{M}\}$ and the strategy that the other leader $l^{2}$ promotes $L^{2} \in\{\mathrm{F}, \mathrm{M}\} \backslash L^{1}$. Without-loss-of-generality, assume that leader $l^{1}$ is more persuasive, that is, $\alpha^{1}(r, k)>\alpha^{2}(r, k)$. By the definition of leader social credibility, follower $i$ believes that with probability $p^{1}\left(\alpha^{1}, \alpha^{2}\right)$ everyone else in the group will follow the advice of leader $l^{1}$ and believes that with probability $1-$ $\mathrm{p}^{1}\left(\alpha^{1}, \alpha^{2}\right)$ the other followers will play the action recommended by leader $l^{2}$. The follower chooses $L^{1}$ since this is her unique response to her prior belief $p\left(\alpha^{1}(\mathrm{r}, \mathrm{k})\right)$. To see this, note that her expected payoff from playing $L^{1}$ is strictly larger than her expected payoff from playing $L^{2}$ : 


$$
E\left[\pi\left(L^{1}, p^{1}\left(\alpha^{1}, a^{2}\right)\right)\right]=p^{1}\left(\alpha^{1}, \alpha^{2}\right) \pi_{c}>\left(1-p^{1}\left(\alpha^{1}, \alpha^{2}\right)\right) \pi_{c}=E\left[\pi\left(L^{2}, p^{2}\left(\alpha^{1}, \alpha^{2}\right)\right)\right]
$$

where the strict inequality follows from A2. This implies that she would never want to play $L^{2}$ or some mixed strategy $q\left(q_{1}, q_{2}\right)$ with $q_{2}>0$. In particular, the follower has no incentive to ignore the advice of the leader and play the babbling equilibrium of the game which is, by A4, the mixed strategy equilibrium with $q_{i}^{*}\left(\frac{1}{2}, \frac{1}{2}\right)$. For the only if part, note that the only case the proof has not covered so far is the case in which $\alpha^{1}(r, k)=\alpha^{2}(r, k)$, since the assumption that $l^{1}$ is the more persuasive leader was without-loss-of-generality. By A2, followers play the mixed strategy equilibrium $q_{i}^{*}\left(\frac{1}{2}, \frac{1}{2}\right)$ whenever the two leaders are exactly equally credible. This completes the proof of the lemma

Proposition 1. Assume A1-A5. In the Weak-Link Game female leaders are less effective than male leaders if and only if $p(\alpha(r, f))<\frac{\pi_{0}}{\pi_{G}}<p(\alpha(r, m))$. In the Leader-Competition Game, female leaders are less effective than male leaders if and only if $\alpha(r, f)<\alpha(r, m)$.

Proof. We will first show the first part of the proposition. Consider the following cases $\frac{\pi_{0}}{\pi_{G}} \leq \mathrm{p}(\alpha(\mathrm{r}, \mathrm{f})) \leq \mathrm{p}(\alpha(\mathrm{r}, \mathrm{m}))$. By lemma 2 followers under female leadership will listen to her and play the equilibrium she recommends. Similarly, followers under male leadership will listen to him and play the equilibrium he recommends. Next consider the cases $p(\alpha(r, f)) \leq p(\alpha(r, m)) \leq \frac{\pi_{0}}{\pi_{G}}$. By lemma 2 followers under either type of leadership will ignore the advice of the leader and play the babbling equilibrium. Lastly, if $p(\alpha(\mathrm{r}, \mathrm{m}))<$ $\frac{\pi_{0}}{\pi_{G}}<\mathrm{p}(\alpha(\mathrm{r}, \mathrm{f}))$, it follows from lemma 2 that women will be more effective leaders than men, whose advice followers will ignore in equilibrium. This completes the proof of the first part of the proposition. The second part follows directly from lemma 3 


\section{Online Appendix}

\section{Additional Descriptions and Analysis}

\subsection{Additional Individual Measures Collected in Experiment 1}

In addition to the measures that are reported in the main text, we collected the following measures from participants.

In Part 3, we first elicited participants' incentivized beliefs about the effectiveness of female and male leaders in our experimental setting. Specifically, we presented all participants with the portraits of the previous session's four CEOs. The portraits were presented to each participant in a random order. Participants were then asked to estimate the average number of hours employees invested in the risky project in Part 2 for each CEO, both for a scenario in which the CEO's picture was shown to employees and for a scenario in which it was not. Participants earned 1 CHF for each estimate that corresponded to the actual average number of hours a group invested in the risky project in Part 2, rounded to the nearest ten.

Employees in the two groups who had not seen the CEO photographs were then shown the portraits of both the male and the female CEO in the current session whose photo had not been shown. We asked each of these participants to guess which of the two CEOs had been their CEO. While not incentivized, this task provides us with information on whether participants could guess from the messages they had received in Part 2 whether their CEO was male or female. Participants in the condition where the leader identity was revealed were asked, instead, whether they were previously familiar with their CEO.

Participants then completed a questionnaire including measures of socioeconomic status, labor market experience, political orientation and risk attitudes. The explicit and implicit measures of attitudes towards gender and leadership concluded were elicited just before payment.

\subsection{Leaders' Messages in Experiment 1}

In this section, we provide more data on the type of messages that male and female leaders send. While any differences in leadership style do not appear to bring about substantial differences in group performance, it is instructive to examine whether women and men differ in how they try to exert influence over the followers in the group. Moreover, 
in additional robustness checks we can test whether the same type of directive is treated differently when it comes from a woman.

We observed some differences in the kinds of messages sent by male and female leaders. In period 7-that is, the first time leaders sent messages—requests of 40 are made by 72 percent of male leaders and 52 percent of female leaders (test of differences in proportions with two-sided alternative, $\mathrm{p}=0.0394)$. This is in line with results presented in Reuben and Timko (2017) who find that around 70 percent of men made initial requests of 40 hours compared to around 50 percent of female leaders. In our sample, men also more often gave an explanation for their investment requests (test of differences in proportions with two-sided alternative, $\mathrm{p}=0.0062$ ). Female leaders made significantly more non-specific requests for positive investment in the risky project in this first period of Part 7 compared to male leaders (test of differences in proportions with two-sided alternative, $\mathrm{p}=0.029$ ).

We next investigate whether the gender of the leader matters for the effectiveness of a message when the leader attempts to turn around the group in period 7 . That is, we test whether followers treat comparable advice of leaders differently when it is given by a woman or a man. To do so, we performed additional regression analysis with data from groups in which the gender of the leader was known. We estimated the following generic model for each of the most common message categories in the first period of Part 2:

$$
\begin{aligned}
\text { hours }_{i, g}=\beta_{0} & +\beta_{1} I_{\text {female leader }}+\beta_{2} I_{\text {category }}+\beta_{3} I_{\text {female leader }} * I_{\text {categroy }} \\
& +\beta_{4} \text { performance part } 1_{g}
\end{aligned}
$$

The dependent variable is hours invested in the risky project by follower $i$ in group $g$. $I_{\text {female leader }}$ and $I_{\text {category }}$ indicate whether the leader was a woman and whether the message sent by a leader in the first period 7 was coded to be in that category. The variable $I_{\text {female leader }} * I_{\text {categroy }}$ is an interaction term. The coefficient $\beta_{3}$ indicates whether advice from women has a different effect than comparable advice by men. The results for the six most common messaged in Period 7 are presented in Table D1 of this Online Appendix.

We once more find that advice by female leaders is equally effective as the advice of male leaders, in this case when we condition on the types of messages used. For instance, while a suggestion of 40 has a strong positive effect on investment in the risky project, this effect is only slightly weaker for women and this difference is not statistically significant. Thus, in general, we do not find that the most effective form of advice is treated systematically differently by followers when it is provided by a female leader than when it comes from a man. Interestingly, the only case in which there seems to be a difference is 
for messages that are written in an assertive tone, which increases the average performance in groups by about 8 hours when men send such messages, but has virtually no effect when the message is sent by a woman. ${ }^{1}$

Finally, as with Period 7, women sent slightly different messages than men across the entirety of Part 2. For example, women much more frequently gave negative feedback about previous outcomes than men (frequency women leaders 30\%, frequency male leaders $8 \%$ ). 51 percent of all messages written by male leaders specifically asked their group to invest 40 hours in the risky project, while this number is 44 percent for female leaders and the difference in proportions is statistically significant (test of difference in proportions with two-sided alternative, $\mathrm{p}=0.0367)$. Also, men significantly more often provided an explanation for the effort level they suggested (test of difference in proportions with twosided alternative, $\mathrm{p}=0.0261$ ). The differences in leadership style were largest initially as Figure D1 of this Online Appendix reveals convergence over time. But, as we have shown in the main paper, these differences do not produce systematically different group outcomes under female leadership compared to male leadership.

\footnotetext{
${ }^{1} 6$ out of the 24 female led groups had a leader that communicated in an assertive tone in the fist period, for groups led by men this number is 7 . We do not see this relationship in groups in which the gender of the leader was not known, which suggests an interaction between gender visibility and assertive tone in messages.
} 
Table D1. OLS Regressions Testing for Differential Responses to Message Content by Leader Gender

OLS Regressions Predicting

Hours invested in Risky Project in Period 7

(Groups with Known Leader)

\begin{tabular}{|c|c|c|c|c|c|c|}
\hline female leader & $\begin{array}{r}2.000 \\
(3.389)\end{array}$ & $\begin{array}{r}-0.349 \\
(2.500)\end{array}$ & $\begin{array}{r}-1.033 \\
(2.604)\end{array}$ & $\begin{array}{r}-2.000 \\
(6.567)\end{array}$ & $\begin{array}{r}0.983 \\
(2.714)\end{array}$ & $\begin{array}{r}-1.826 \\
(2.267)\end{array}$ \\
\hline suggest 40 & $\begin{array}{r}14.82 * * * \\
(2.961)\end{array}$ & & & & & \\
\hline $\begin{array}{l}\text { fem leader } X \\
\text { suggest } 40\end{array}$ & $\begin{array}{r}-2.996 \\
(3.480)\end{array}$ & & & & & \\
\hline $\begin{array}{l}\text { suggest ambiguous } \\
\text { positive }\end{array}$ & & $\begin{array}{r}-0.959 \\
(3.831)\end{array}$ & & & & \\
\hline $\begin{array}{l}\text { fem leader X } \\
\text { suggest ambiguous } \\
\text { positive }\end{array}$ & & $\begin{array}{r}-2.684 \\
(4.632)\end{array}$ & & & & \\
\hline appeal trust & & & $\begin{array}{r}-1.696 \\
(3.834)\end{array}$ & & & \\
\hline $\begin{array}{l}\text { fem leader X } \\
\text { appeal trust }\end{array}$ & & & $\begin{array}{r}0.173 \\
(5.341)\end{array}$ & & & \\
\hline explanation & & & & $\begin{array}{r}2.939 \\
(6.567)\end{array}$ & & \\
\hline $\begin{array}{l}\text { fem leader X } \\
\text { explanation }\end{array}$ & & & & $\begin{array}{r}2.433 \\
(7.012)\end{array}$ & & \\
\hline assertive tone & & & & & $\begin{array}{r}8.077^{* * * *} \\
(2.186)\end{array}$ & \\
\hline $\begin{array}{l}\text { fem leader X } \\
\text { assertive tone }\end{array}$ & & & & & $\begin{array}{r}-7.246^{* *} \\
(3.537)\end{array}$ & \\
\hline supplicating tone & & & & & & $\begin{array}{r}-11.67 \\
(13.01)\end{array}$ \\
\hline $\begin{array}{l}\text { fem leader X } \\
\text { supplicating tone }\end{array}$ & & & & & & $\begin{array}{r}12.91 \\
(13.67)\end{array}$ \\
\hline Performance part 1 & $\begin{array}{r}0.338 * * * \\
(0.118)\end{array}$ & $\begin{array}{c}0.305^{*} \\
(0.160)\end{array}$ & $\begin{array}{l}0.271 * \\
(0.144)\end{array}$ & $\begin{array}{r}0.327 * * \\
(0.140)\end{array}$ & $\begin{array}{r}0.223 \\
(0.152)\end{array}$ & $\begin{array}{r}0.258 \\
(0.158)\end{array}$ \\
\hline Constant & $\begin{array}{r}23.45^{* * * *} \\
(2.896)\end{array}$ & $\begin{array}{r}32.96 * * * \\
(1.920)\end{array}$ & $\begin{array}{r}33.39 * * * \\
(2.067)\end{array}$ & $\begin{array}{r}30.40 * * * \\
(6.354)\end{array}$ & $\begin{array}{r}31.03 * * * \\
(2.118)\end{array}$ & $\begin{array}{r}33.67 * * * \\
(1.534)\end{array}$ \\
\hline $\mathrm{N}$ of followers & 300 & 300 & 300 & 300 & 300 & 300 \\
\hline
\end{tabular}

Notes. Robust standard errors in parentheses (clustered at the group level). *Significant at the $10 \%$ level, ${ }^{* *}$ at the $5 \%$ level, $* * *$ at the $1 \%$ level. 


\section{Figure D1. Frequency of Message Categories Over Time by Gender of the Leader}
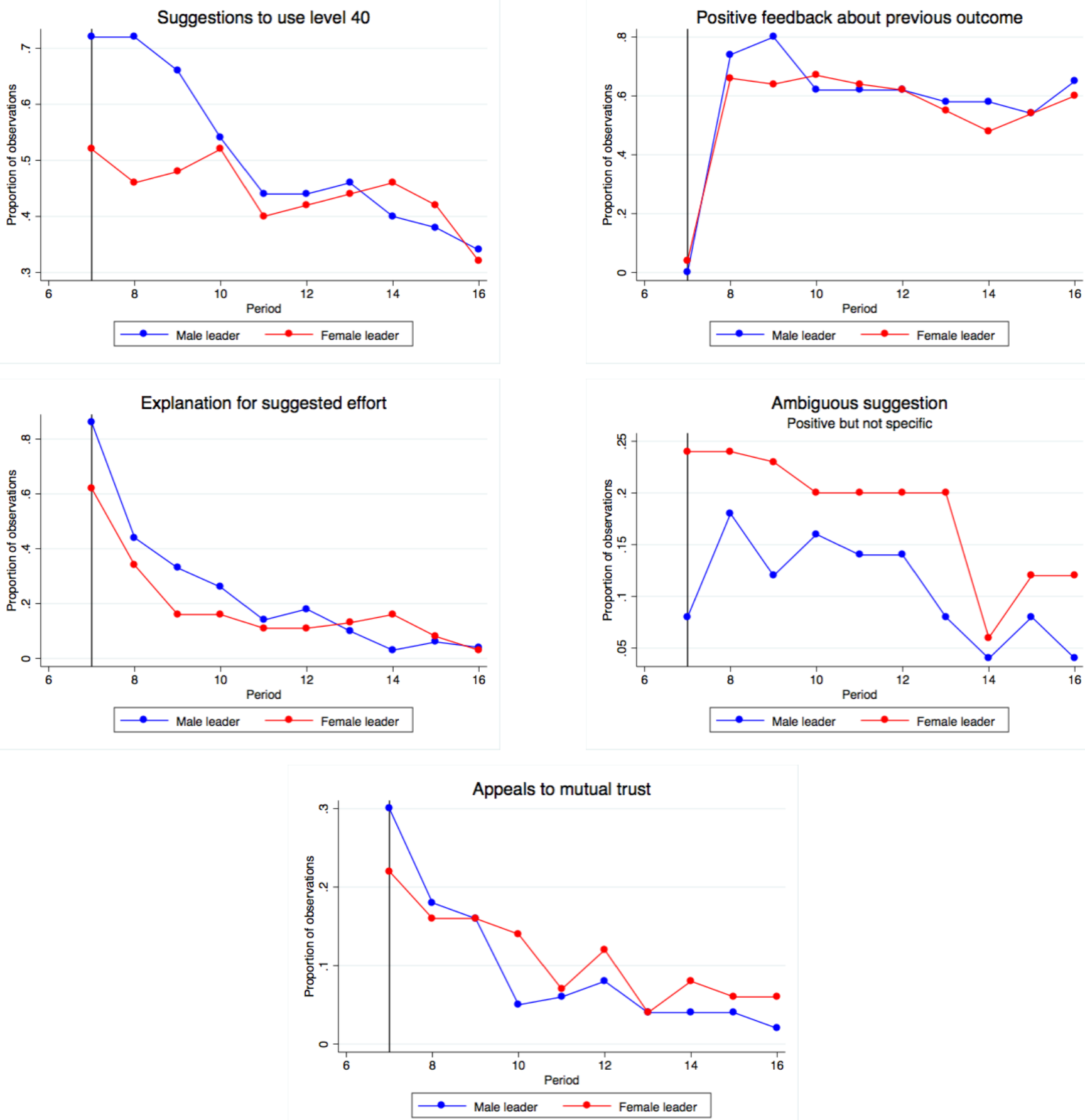

Notes. Figures display frequency of message categories by gender of the leader over the course of Part 2. The five most frequent message categories overall are displayed. 


\subsection{Data Selection for Figure 1}

In this section, we describe how we selected the data from the two related studies Grossman et al. 2019 and Reuben and Timko 2018 for Figure 1. We thank Ernesto Reuben and Philipp Grossman for sharing their original data set with us.

In Reuben and Timko 2018, the strategy space in the weak-link game (WLG) ranges from 0 to 40 hours in increments of 10 . Up to period 8, groups played the WLG without a leader. After period 8, a group leader was chosen endogenously: group members had to volunteer to become a leader and were, then, depending on the treatment arm, either 1) randomly selected from the set of volunteers or 2) elected by everyone in the group. Leaders were selected for 3 periods after which a new leader was appointed. For Figure 1 of the main text, we use data from the authors' random selection treatment. This comes closest to our stratified random selection among all women and all men who participated in a session. In addition, we consider data from the first time a leader was introduced, that is, in period 9 of the super game. This ensures a high degree of comparability across the three studies since, across all studies, we are comparing performance of male and female leaders when groups are exposed to leadership for the first time. The unit of observation is the leader.

In Grossman et al. 2019 the strategy space in the WLG ranges from 0 to 3 USD in increments of 1. Up to period 10, groups played the WLG without a leader. After period 10, a leader gave a semi-scripted speech to all groups in a session. Then, groups were reformed and played 10 more rounds of the WLG. Grossman et al. also followed a stratified random selection of leaders where stratification was at the session level, that is, some sessions were "female leader" sessions and others were not. Again, for the treatment comparison depicted in Figure 1, we use data from period 11 of this experiment, in which the WLG was played right after the leader had given the speech. The unit of observation is the leader. 


\section{Instructions}

This Online Appendix reproduces the handout instructions as they were distributed to participants.

\subsection{Experiment 1 Instructions}

Initially, the participants received only the instructions for Part 1. After this part of the study was completed, they also received the instructions for Part 2. An experimenter read the instructions out loud at the beginning of each part.

\subsection{Experiment 2 Instructions for CEOs}

\subsection{Experiment 2 Instructions for Investors}

\subsection{Instructions for Expert Prediction Task}




\subsection{Experiment 1 Instructions}

\section{INTRODUCTION FOR THE STUDY}

This is an experiment in decision-making. The experiment has 2 parts. Part 1 comprises 6 rounds of a game, and Part 2 comprises 10 rounds. You find the instructions for Part 1 on your desk in front of you. I will read these instructions out loud in order for all participants to have the same information. You may read along as I read the instructions aloud.

After Part 1 is completed you will receive instructions that describe Part 2. Note that what happens in Part 1 does not influence the procedures for Part 2.

In addition to a $15 \mathrm{CHF}$ participation fee you will be paid any additional money you accumulate during the experiment. All payoffs during the experiment are denominated in Experimental Currency Units (ECU). At the end of the experiment, ECU will be converted to Swiss Francs at a rate of 1 CHF per 150 ECU. The exact amount you receive, in addition to the participation fee, will be determined during the experiment, and will depend on your decisions and on the decisions of others. You will be paid in private, in cash, at the end of the experiment.

If you have any questions during the experiment, please raise your hand and wait for an experimenter to come to you. Please do not talk, exclaim, or try to communicate with other participants during the experiment. Participants intentionally violating the rules may be asked to leave the experiment without payment. 


\section{INSTRUCTIONS FOR PART 1}

At the beginning of today's study all participants are randomly assigned to a firm that you can think of as, for example, a small start-up. Each firm has 1 CEO and a staff of 5 employees. The 6 participants will remain together in the same firm for all 16 rounds of the experiment. At the onset of the study, the computer randomly allocated participants to firms, and to either the role of CEO or an employee. Your role will be displayed in the upper right corner of your screen. All participants remain in the same role throughout the 16 rounds of the experiment.

Below, we describe Part 1 of the experiment, and explain the task of the employees and the CEO in detail.

\section{The Task}

\section{- Employees}

In each of the 16 rounds of the experiment, the 5 employees decide how to allocate their work time. Each round can be thought of as a workweek and employees spend 40 hours per week at their firm. Each employee has to choose how to allocate the 40 hours between two projects, a safe project and a risky project.

Employees can choose to spend $0,10,20,30$, or 40 hours on the risky project. The remaining hours will be spent on the safe project. For example, if an employee spends 30 hours on the risky project, the remaining 10 hours will be spent on the safe project. If, instead, an employee spends 10 hours on the risky project, the remaining 30 hours will be spent on the safe project.

The employees of a firm will remain anonymous throughout the study. In other words, the actions employees take in this experiment will remain confidential.

\section{- CEOs}

In Part 1 the CEO of the firm observes the employees' actions, but makes no active decision. 


\section{Payoffs}

In each round of the game, employees and CEOs earn a payoff. Your total payoff from today's experiment consists of the sum of what you have earned over all 16 rounds of parts 1 and 2 . We will now describe, in detail, how these payoffs are determined for the 5 employees and for the CEO in each firm.

\section{- Employee Payoff per Round}

As an employee, you can influence your payoff, and the payoff of the other employees in your firm, through how you decide to allocate your time between the safe and the risky project. The safe and the risky project have different payoffs.

Payoff from the safe project: You receive 200 ECU for allocating all of your time to the safe project. For each hour that you allocate to the risky project instead of the safe project, you give up 5 ECU. For example, if you decide to spend 20 hours on the risky project you give up $100 \mathrm{ECU}$. The payoff from the safe project is paid out to the employee independently of what anyone else in the firm does in that round.

Payoff from the risky project: All employees in the firm receive the same payoff from the risky project. This payoff depends on two things. Specifically, it depends on the minimum number of hours allocated to the risky project by any employee in the firm, and on the rate of return to the risky project.

1. The employee payoff from the risky project depends on the minimum number of hours allocated to the risky project by any employee in the firm. The minimum is the smallest number of hours chosen for the risky project. For example, suppose the 5 employees choose to allocate $20,10,40,10$ and 40 hours to the risky project. Then, 10 hours is the minimum number of hours allocated to the risky project within the firm.

2. The employee payoff from the risky project also depends on the rate of return to the risky project. This rate of return applies equally to all employees of a firm.

The rate of return can vary from round to round because of factors beyond the firms' control, like market competition. It can be either low or high. The low rate of return is 5 and the high 6 . At the end of each round, the computer will randomly select a rate of return for each firm. The two possible rates of return are equally likely to be selected. Thus, in each round the probability is $1 / 2$ that a specific rate of return is randomly selected. 


\begin{tabular}{|l|l|}
\hline \multicolumn{2}{|l|}{ Rate of Return to the risky project } \\
\hline Low & 5 \\
\hline High & 6 \\
\hline
\end{tabular}

The payoff that each employee receives in a round from the risky project is the rate of return multiplied by the minimum number of hours an employee in the firm spends on the risky project.

The employee payoffs can also be represented by the following formula:

Employee's payoff $=200-$ Hours employee spends on risky project $* 5$ + Minimum hours spent on risky project * Rate of return

If you do not find this formula useful, don't worry about it. It is given to you as an additional way to understand the payoffs. You will see tables that describe the possible payoffs any time you have to make a choice.

The following examples illustrate how payoffs are determined in this game.

\section{- Example 1}

Suppose that in a round, Employee $A$ chooses to spend 10 hours on the risky project. Suppose the other 4 employees in the firm each spend 10,20,30, and 40 hours on the risky project. This means that the minimum number of hours allocated to the risky project within the firm is 10 hours.

Employee A's payoff then equals: 200 - (10 hours * 5) + (10 hours * the rate of return). Suppose that at the end of the round the computer randomly selects 6 as the rate of return. Employee A's payoff is then $200-10 * 5+10 * 6=210$.

\section{- Example 2}

Suppose, instead, that Employee A decides to spend 30 hours on the risky project. Again, suppose the other 4 employees spend 10,20, 30 and 40 hours on the risky project and that the computer randomly selects 6 as the rate of return. This means that the minimum number of hours allocated to the risky project within the firm is again 10 hours.

Employee A's payoff then equals: $200-(30$ hours $* 5)+(10$ hours * the rate of return). Since the computer randomly selects 6 as the rate of return, Employee $A^{\prime}$ 's payoff is then $200-30 * 5+10 * 6=110$. 
You have the printout of the payoff table for both possible rates of return-5 or 6 - on a separate sheet. The payoff tables include all the information employees will need in order to make their decisions. We will illustrate how to read these tables with examples 1 and 2 from the previous page.

Take Employee A's perspective in example 1, who chooses to spend 10 hours on the risky project. Recall that, in the example, the computer randomly selected the rate of return of 6 , so look at the bottom table. To find out how much you would earn, you would first find the row in the table that corresponds to your time allocation. In this example, this is the second row from the top with the entries " 10 " in the column "my hours spent on the risky project" and " 30 " in the column "my hours spent on the safe project." Columns 1-5 indicate how your earnings would change with the actions that the other employees take. In example 1, 10 is the minimum number of hours that other employees allocate to the risky project. This corresponds to the second column. The corresponding entry in the table is 210 , the payoff that we also calculated on the previous page.

Suppose, instead, that the computer randomly selected the rate of return of 5 . In that case, you would look at the top table. The second row and second column in this case give a payoff of 200, which is also the payoff from the formula: $200-(10$ hours $* 5)+(10$ hours $*$ the rate of return $)=$ $200-50+50=200$.

Next, take Employee A's perspective in example 2, who chooses to spend 30 hours on the risky project. Returning to the case where the computer randomly selected the rate of return of 6 , look again at the bottom table. To find out how much you would earn, you would again find the row in the table that corresponds to your time allocation. In this example, this is the fourth row from the top with the entries " 30 " in the column "my hours spent on the risky project" and " 10 " in the column "my hours spend on the safe project." The action of the other employees does not change and the second column is still the correct column at which to look. The corresponding entry in the table is 110 , the payoff that we also calculated on the previous page.

Finally, suppose again that the computer instead randomly selected the rate of return of 5 , which means you should look at the top table. The third row and second column in this case give a payoff of 100 , which is also the payoff from the formula: $200-(30$ hours $* 5)+(10$ hours * the rate of return) $=200-150+50=100$.

Employees can refer to these payoff tables at any point at which they make a decision. They will be visible on the decision screen for employees, which is shown on the next page. Employees choose the number of hours they work on the risky project by entering the corresponding number, either $0,10,20,30$ or 40 in the box in the middle of the screen. 


\section{Decision screen for employees}

\section{Round 1 out of 2 | Your Role: Employee}

Participant \# 2

Below you see the tables that show your possible payoffs, depending on your decision, the decision of the other employees in your firm and the rate of return to the risky project.

To choose a number of hours you want to spend on the risky project, type in a value in the corresponding box. When you have made your final decision, click on the button labelled "Continue" to submit your answer for this round.

Currently, you do not know the choices of the other employees in your firm. But you will find out the minimum number of hours spent on the risky project immediately after this round, once everyone submits their choices.

\begin{tabular}{|c|c|c|c|c|c|c|}
\hline & \multicolumn{6}{|c|}{$\begin{array}{r}\text { Number of hours I alloca } \\
\text { Type in } 0,10,2\end{array}$} \\
\hline & \multirow[b]{2}{*}{$\begin{array}{l}\text { My Hours } \\
\text { on The } \\
\text { Safe } \\
\text { Project }\end{array}$} & \multicolumn{5}{|c|}{$\begin{array}{l}\text { Minimum Hours Spent by Other Employees on The } \\
\text { Risky Project }\end{array}$} \\
\hline $\begin{array}{l}\text { My Hours } \\
\text { on The } \\
\text { Risky } \\
\text { Project } \\
\end{array}$ & & 0 & 10 & 20 & 30 & 40 \\
\hline 0 & 40 & 200 & 200 & 200 & 200 & 200 \\
\hline 10 & 30 & 150 & 200 & 200 & 200 & 200 \\
\hline 20 & 20 & 100 & 150 & 200 & 200 & 200 \\
\hline 30 & 10 & 50 & 100 & 150 & 200 & 200 \\
\hline 40 & 0 & 0 & 50 & 100 & 150 & 200 \\
\hline & & & & of retu & & \\
\hline
\end{tabular}

\section{the risky project.}

\begin{tabular}{|c|c|c|c|c|c|c|}
\hline \multirow[b]{2}{*}{$\begin{array}{l}\text { My Hours } \\
\text { on The } \\
\text { Risky } \\
\text { Project }\end{array}$} & \multirow[b]{2}{*}{$\begin{array}{l}\text { My Hours } \\
\text { on The } \\
\text { Safe } \\
\text { Project }\end{array}$} & \multicolumn{5}{|c|}{$\begin{array}{l}\text { Minimum Hours Spent by Other Employees on The } \\
\text { Risky Project }\end{array}$} \\
\hline & & 0 & 10 & 20 & 30 & 40 \\
\hline 0 & 40 & 200 & 200 & 200 & 200 & 200 \\
\hline 10 & 30 & 150 & 210 & 210 & 210 & 210 \\
\hline 20 & 20 & 100 & 160 & 220 & 220 & 220 \\
\hline 30 & 10 & 50 & 110 & 170 & 230 & 230 \\
\hline 40 & 0 & 0 & 60 & 120 & 180 & 240 \\
\hline & & & & of ret & & \\
\hline
\end{tabular}

The rate of return can be low (5) or high (6) and is determined randomly by the computer after you have made your decision. 


\section{- CEO Payoff per Round}

Each round, the CEO of the firm will receive a payoff equal to the average payoff of all employees in the firm.

\section{Feedback at the end of each round}

At the end of each round, each employee will receive a summary of what happened in that round. This feedback includes

- the rate of return to the risky project,

- the number of hours that the particular participant spent on the risky project,

- the minimum number of hours spent on the risky project among the employees in the firm,

- the participant's own payoff for that round,

- the participant's own accumulated payoffs through the current round,

- the CEO's payoff for that round, and

- the CEO's accumulated payoffs through the current round.

All employees will also see a summary of this information for the preceding rounds.

The CEO will also receive a summary of what happened in each round, including

- the rate of return to the risky project,

- the minimum number of hours spent on the risky project within the firm,

- the CEO's payoff for that round, and

- the CEO's accumulated payoffs through the current round.

The CEO will also see a summary of this information for the preceding rounds.

Before you make any choices, we would like you to answer some control questions. They test whether you understand the procedures of the experiment. The computer will guide you through the control questions.

If you have any questions please raise your hand and wait for an experimenter to come to you.

Once everyone has completed the control questions, Part 1 of the study will begin. 


\section{INSTRUCTIONS FOR PART 2}

We will now proceed with the second part of the experiment (Rounds 7-16). Part 2 differs from Part 1 in two ways:

1. First, the CEO in each firm now has an active role. Consequently, the way the CEO's payoffs are determined for each round is different than in Part 1.

2. Second, the rates of return to the risky project are higher. Otherwise, the way in which employees' payoffs are determined does not change.

\section{Employees' Task}

The employees' task does not change from Part 1 to Part 2. There are again 5 employees in each firm. Each employee will again allocate 40 hours between a risky project and a safe project and will receive a payoff from the risky project based on the minimum number of hours any employee in the firm allocates to the risky project.

\section{CEO's Task}

In Part 2, the firm CEO will have an active role. In each round, the CEO will send a written message to the 5 employees in the firm. All 5 employees in a firm will read the CEO's message before deciding how to allocate their time between the risky project and the safe project. The message will be sent through a message box on the screen that will be available for 90 seconds at the onset of each round. During these 90 seconds the CEO will draft a message to the employees in the firm. The CEO will be able to view the message before sending it. Once the CEO sends the message, the CEO and the employees are advanced to the next stage of the game. At this stage, employees will see the message of their CEO and decide how to allocate their time.

Except for the following restrictions, CEOs can type whatever they want in the message:

\section{Restrictions on Messages}

1. The message sent to employees in a round must contain at least 15 characters.

2. Please write in English.

3. Please do not send any personal information (for example, writing about your age or field of study).

4. Please refrain from using obscene or offensive language.

In some firms, the CEO's portrait that was taken at the beginning of the experiment will be presented to the employees together with the CEO's message. The computer randomly determines whether or not the portrait is shown to the firm's employees in Part 2. If it is shown, it will appear in all 10 rounds of Part 2 and will be shown to all of the firm's employees. The CEOs will not know whether their portrait is attached to the message. However, all employees will know whether or not they and other employees see the CEO's portrait. The CEOs will never see the portraits of the employees in their firm, whether their portrait is shown to the employees or not.

\section{Payoffs}


The total payoff that will be paid out at the end of today's experiment is the payoff you accumulated in rounds 1-6 plus the payoff you will accumulate in rounds 7-16.

\section{Employees' Payoffs per Round}

The way in which payoffs are calculated for employees remains the same in Part 2 as in Part 1. However, the rate of return to the risky project has increased. The rate of return now has two new possible values: a low return of 8 and a high return of 10. Again, the computer will randomly select one rate of return at the end of each round. The probability that a specific rate of return is selected is $1 / 2$.

\begin{tabular}{|l|c|}
\hline Rate of Return to the risky project \\
\hline Low & 8 \\
\hline High & 10 \\
\hline
\end{tabular}

Again, you have a printout of the payoff table for both possible rates of return -8 or $10-$ on a separate sheet. The payoff tables include all the information employees will need in order to make their decisions.

Let's revisit the two examples from Part 1 to see how the new rates of return matter for employees' payoffs in each round of Part 2:

\section{- Example 1}

In this example Employee $A$ spends 10 hours on the risky project and the other 4 employees each spend $10,20,30$, and 40 hours on the risky project. This means that the minimum number of hours allocated to the risky project within the firm is 10 hours.

Employee A's payoff then equals: $200-(10$ hours * 5$)+(10$ hours * the rate of return). Suppose that at the end of the round the computer randomly selects 10 as the rate of return. Employee A's payoff is then $200-10 * 5+10 * 10=250$ ).

\section{- Example 2}

Suppose, instead, that Employee A decides to spend 30 hours on the risky project. Again, suppose the other 4 employees spend 10,20, 30 and 40 hours on the risky project and that the computer again randomly selects 10 as the rate of return. This means that the minimum number of hours allocated to the risky project within the firm is again 10 hours.

Employee A's payoff then equals: $200-(30$ hours * 5$)+(10$ hours * the rate of return). Since the computer randomly selects 10 as the rate of return, Employee A's payoff is then $200-30 * 5+10 * 10=150$.

\section{CEO's Payoff per Round}

The CEO will have an active role in Part 2 of the experiment, which is also reflected in the CEO's payoffs. In rounds 7-16, the CEO's payoff for each round will depend partly on the actions of the employees. Specifically, the CEO's payoff has a fixed and a variable component. The CEO's payoff primarily depends on the variable component. 


\section{- $\quad$ Fixed component}

In each round the CEO receives a fixed payment of 150 ECU. The CEO receives this for typing a message in that round.

\section{- Variable component}

The variable component depends on 1) the minimum number of hours that the employees in the firm allocate to the risky project and 2) the rate of return to the risky project.

Recall that the rate of return is equally likely to be either 8 or 10 , and is determined randomly by the computer.

The CEO's payoffs can be represented by the following formula:

$$
\text { CEO's payoff }=150+\text { Rate of return * Minimum hours spent on risky project }
$$

If you do not find this formula useful, don't worry about it. It is given to you as an additional way to understand the payoffs. You will see tables that describe the possible payoffs any time you have to make a choice.

You have the CEO payoff table on a separate sheet. This table shows the CEO's payoffs for every possible value of the minimum number of hours spent on the risky project and for both rates of return, 8 and 10 .

Let's look again at some examples to see how the CEO's payoffs are determined in Part 2.

\section{- Example 1}

Suppose that in a round, the 5 employees spend 10, 20, 30, 30 and 40 hours on the risky project, so that 10 hours are the minimum number of hours allocated to the risky project. The CEO's payoff then equals: $150+(10$ hours * the rate of return). Suppose that at the end of the round the computer randomly selects 10 as the rate of return. The CEO's payoff is then $150+10 * 10=250$.

\section{- Example 2}

Suppose, instead, that in a round, the 5 employees spend 30, 30, 40, 40 and 40 hours on the risky project, so that 30 hours are the minimum number of hours allocated to the risky project. The CEO's payoff now equals: $150+(30$ hours * the rate of return). Again, suppose that at the end of the round the computer randomly selects 10 as the rate of return. The CEO's payoff is then $150+30 * 10=450$.

\section{Feedback at the end of each round}

At the end of every round in Part 2, the employees and the CEO will receive the same detailed feedback as in Part 1 about what happened in the latest round and preceding rounds. 
Before we begin Part 2 of the experiment, everyone will be asked some additional control questions. This is to ensure that all of you understand the role that CEOs have in Part 2 and their payoffs. Once everyone answers all the questions correctly, round 7 of the game will start immediately with the screen on which CEOs can enter the message to their employees.

Appendix D - Instructions Experiment 2

The following pages reproduce the instructions as they were given to the study participants who participated as CEOs or as investors. 


\subsection{Experiment 2 Instructions for CEOs}

\section{INSTRUCTIONS}

This booklet contains the instructions for today's study. Please start by reading the complete instructions in order to understand the study. Once you have read the instructions, you will first answer a few questions on the screen to make sure that you understood the instructions, before the study starts.

\section{Portraits}

During the session, we will call each of you individually, one at a time, to have your portrait taken. When it is your turn, the experimenter will call your participant number that is written on the number card that you have received. When your number is called, please exit this room and go to the directed area, where a photographer will take your portrait. When your portrait was taken, please return to this room immediately and inform the experimenter that you are back so that the experimenter can call the next person to step outside this room in order to have the portrait taken.

To save time, please be prepared to go outside directly once your participant number is called. Please remove any hats and coats and leave them in this room. After your portrait is taken, you will return to this room to complete the study.

\section{Introduction to the study}

This is a study on decision-making. You will be paid a $15 \mathrm{CHF}$ participation fee, in cash, at the conclusion of today's session.

You may also accumulate additional money based on your actions and the actions of other participants in the study. During the study, as explained in more detail below, you will interact with participants who take part in different sessions that will occur in the coming weeks. Your final payoff will not be known until later, after all participants have taken part in the experiment. Your payment for this part of the study will be mailed to you at the end of the experiment, after the last session. For this purpose, you will receive an envelope at the end of today's session that you should complete with the address at which you would like to receive your payment.

If you have any questions during the study, please raise your hand and wait for an experimenter to come to you. Please do not talk, exclaim, or try to communicate with other participants during the study. Participants intentionally violating the rules may be asked to leave the study without payment. 


\section{Overview of the study}

In this study, participants are assigned either to the role of a CEO, or to the role of an investor. All participants in this session have been assigned the role of a CEO, and you will keep this role throughout the study. Participants in the role of investors will participate in later sessions, to be conducted in the coming weeks.

You can think of your role as being the CEO of a small start-up firm. As the CEO, your task is to attract as many investors as possible to your company. By attracting investors to your firm, rather than these investors investing in competing firms, you can earn more money. Investors care about your ability to attract other investors and to select products that can be successfully developed and marketed.

Your main tasks today will be to write a message to attract investors, and to select products that your firm will develop. We will describe below in detail how you attract investors and select products. Investors will want to invest in your firm if they believe that you will also attract other investors and that you will make good product choices.

\section{Investors choosing firms}

Today's session consists only of CEOs. Investors will take part in future sessions.

Specifically, in future sessions, investors will play several rounds of a game, in which they have to choose between competing firms. Your main task in this study is to attract investors so that they choose your firm.

In each round, investors face a simple choice: choose to invest in either your firm or a competing firm. The investors earn money if they both choose to invest in the same firm; otherwise they earn nothing. The game between the two investors can thus be described by the following table:

Investor B selects ...

\begin{tabular}{|c|c|c|c|}
\hline \multirow{3}{*}{$\begin{array}{l}\text { Investor A } \\
\text { selects . . }\end{array}$} & & Your firm & Competing firm \\
\hline & Your firm & $\begin{array}{c}\text { Both investors earn } \\
\text { money; } \\
\text { you earn money }\end{array}$ & $\begin{array}{c}\text { Both investors earn } \\
\text { nothing; } \\
\text { you earn nothing }\end{array}$ \\
\hline & $\begin{array}{c}\text { Competing } \\
\text { firm }\end{array}$ & $\begin{array}{c}\text { Both investors earn } \\
\text { nothing; } \\
\text { you earn nothing }\end{array}$ & $\begin{array}{c}\text { Both investors earn } \\
\text { money; } \\
\text { you earn nothing }\end{array}$ \\
\hline
\end{tabular}

In each round of the study, the two investors each choose one of the two firms independently and simultaneously. This means that when an investor decides in which firm to invest, this investor does not observe the choice that the other investor is making at the same time. Investors have up to 90 seconds to decide in each round. 
You earn money only when both investors select your firm, otherwise you earn nothing. If both investors select the competing firm, then the CEO of the competing firm earns money. Later, we will describe the exact payoff you receive in case two investors select your firm in a round.

Investors earn money if they both select the same firm, and they earn zero otherwise. The exact amount they earn when they both pick the same firm will depend on whether the products selected by that firm's CEO are successful. Below, we will describe in detail how these payoffs are determined.

In each round, new groups of two investors and two CEOs will be formed at random. You will only be paired with the same CEO of a competing firm, or with the same investors, once. After each round, a new group of two CEOs and two investors will be formed so that you will never interact with any of the same other participants twice. No investor will be informed about any outcomes, or the choices of any other investors, until the end of their session. Note that this means that each of the rounds is independent, and what happens in one round does not influence what happens in any other round.

You will not find out about any choices that other CEOs make today, nor will any other CEOs find out about your choices.

\section{Messages from CEOs}

In order to convince investors to select your firm, you and the CEO of the competing firm will each write a message that investors can see while they are making their choices. Thus, your main task in today's study will be to write a message that you believe will convince the two investors to both select your firm.

In the later sessions, when investors are making choices, the two investors who are paired with you in a round will see your message, and the message from the CEO of the competing firm. The two messages will be displayed as in the following example: 
This CEO's message:

Message 1
This CEO's message:

Message 2

Investors will select one of the two firms by clicking next to the message from the corresponding CEO. The order in which the CEOs messages appear will be random for each investor, meaning that the message one investor sees on the left side of the screen may appear either at the left or the right side of the other investor's screen. That is, investors do not know whether the other investor also sees the two messages in the same order, or in the opposite order.

In some rounds, investors will also see the portraits of the two CEOs along with the CEOs' messages. Investors will either see the portraits of both CEOs or of none. The computer randomly determines whether or not the portraits are shown to the investors in a round. However, if the portraits are shown, they are always presented together, and always to both investors. The CEOs' messages will be the same, regardless of whether or not the portraits are shown. Neither you nor any other CEOs will see the portraits of the other CEOs.

\section{Your tasks as the CEO today}

During today's session you have two tasks as a CEO: writing a message and selecting products.

\section{Writing a message}


All CEOs will write a message to the investors. As explained above, in each round, the investors will read the messages from two CEOs before deciding in which of the two firms to invest. The message is therefore a possibility for you to motivate why the two investors in a round should both choose your firm.

In the remainder of today's session, you will draft a message to the investors through a text box that you will see on your screen once the study starts. In total, you have up to 40 minutes to finalize your message. Your message should convey to investors why they should pick your firm. You will be able to review the message before submitting it.

Except for the following restrictions, CEOs can type whatever they want in the message:

5. The message sent to the investors must contain between 60 characters (around 10 words) and 700 characters (around 100 words).

6. Do not use line breaks in your message since they will not be displayed to investors.

7. Try to avoid using special characters (e.g., “ä", “\&”, “@”) since your message may not display properly.

8. Please write in English.

9. Please do not send any personal identifying information (for example, writing your name or age).

10. Please refrain from using obscene or offensive language.

\section{Selecting products}

At the end of today's session, after writing your message, you will select 3 out of 6 possible products that your firm will develop and sell. To select products you will see the names of 6 different possible products on your screen. You will select products by clicking on their names. Note that you will be asked to select exactly three products, not more or less.

Before the participation of the investors, the computer will randomly draw 1 of the 6 products to be the successful product for this study. Each of the 6 products thus has an equal chance of being successful. Investors earn more money by picking the same firm, but they earn even more money by jointly picking a firm whose CEO selected a successful product.

Note that, at the time they make their investment choices, investors will not know the specific product choices by either of the CEOs.

\section{Payoffs for investors}

Investors will receive a participation fee of CHF 15 for participating in the experiment. Even though investors will play many rounds of the game, each investor will only be paid additional earnings based on the outcome in one randomly chosen round of the game. 
Specifically, investors' payoffs in the selected round will be determined as follows:

- Investors receive 0 CHF (in addition to the CHF 15 participation fee) if they do not both pick the same firm in the selected round.

- Investors receive CHF 15 (in addition to the CHF 15 participation fee) if they pick the same firm and that firm's CEO does not select the successful product.

- Investors receive CHF 25 (in addition to the CHF 15 participation fee) if they pick the same firm and that firm's CEO selects the successful product.

That means that by selecting the successful product and attracting both investors to choose your firm, you generate a payoff of $25 \mathrm{CHF}$ for each of the two investors.

\section{Payoffs for CEOs}

Unlike investors, CEOs can earn money for every round in which their message is shown to investors. Your message will be used in a total of at least 24 rounds, but possibly more. In each of these rounds, you will be paired with a different competing firm, and different investors. You may earn money in each of these rounds, if you convince both investors to choose your firm.

The only thing that matters for your payoff in a round is whether or not both investors select your firm in that round. Specifically, your payoffs across all rounds will be determined as follows:

- If both investors select your firm in a round, you will earn a payoff of $2 \mathrm{CHF}$ for that round (in addition to your CHF 15 participation fee and your earnings in all other rounds)

- Otherwise, you will receive $0 \mathrm{CHF}$ for that round.

The final payoff for every CEO is the sum of these payments across all rounds of the study.

As we mentioned earlier, during the coming weeks we will invite participants who will perform the role of investors in future laboratory sessions. These investors will play several rounds of the investment game and in at least 24 of these rounds your firm will be one of the two competing firms. At the end of the study, we will calculate the total payoff that you have received across all of the rounds in which your firm was one of the two choices, across all of the sessions of the experiment. This money will be mailed to you by post.

Your show up fee of $15 \mathrm{CHF}$ will be paid out today, at the end of the session.

\section{Feedback}

No feedback about the outcomes of the investor's choices or the CEOs product choices will be given to participants until the end of their participation in this study, when participants receive their payment. That means that neither the CEOs, nor the investors, will know anything about the outcomes of specific rounds before their participation in the study is over. 


\section{Start of the study}

Before you make any choices, we would like you to answer some control questions. These questions test whether you understand the procedures described in these instructions.

The computer will guide you through the control questions. Once you have completed these questions, you will see a text box into which you can write your message. You will have up to 40 minutes to write a message. During this time, you will also have your portrait taken, in case it has not been taken, yet. When it is your turn to have your portrait taken, the experimenter will call your participant number. It is important that you return to this room immediately after your portrait was taken. Don not forget to inform the experimenter that you are back when you return to this room after your portrait was taken.

At the end of the study, you will complete a short questionnaire and will then receive your participation fee.

If you have any questions now or later in the study please raise your hand and wait for an experimenter to come to you.

Please click the "continue" button to start the control questions. 


\title{
2.3Experiment 2 Instructions for Investors
}

\author{
INSTRUCTIONS
}

Welcome to today's study. You find the instructions for today's study on the desk in front of you. The instructions will be read aloud in order for all participants to have the same information. You may read along as you listen to the instructions. Once you have listened to the full instructions, you will first answer a few questions on the screen to make sure that you understood the instructions, before the study starts.

\section{Introduction to the study}

This is a study on decision-making. You will be paid a $15 \mathrm{CHF}$ participation fee, in cash, at the conclusion of today's session.

You may also accumulate additional money based on your actions and the actions of other participants in the study. During the study, as explained in more detail below, you will interact both with participants who are here in this session, as well as with participants who took part in different sessions that occurred in the previous weeks.

If you have any questions during the study, please raise your hand and wait for an experimenter to come to you. Please do not talk, exclaim, or try to communicate with other participants during the experiment. Participants intentionally violating the rules may be asked to leave the study without payment.

\section{Overview of the study}

In this study, participants are assigned either to the role of an Investor, or to the role of a CEO. All participants in this session have been assigned the role of an Investor, and you will keep this role throughout the study. The role of CEO is performed by participants who already took part in previous sessions. These participants were paid a fixed payment for their participation, but may also receive additional money based on the choices made by you, as Investors, in today's session.

As an Investor, your task is to decide between two competing firms in which you can invest. Successful firms are those who attract the investment of as many investors as possible, and whose CEOs make good product choices. By selecting successful firms, you can earn more money. Below we describe in detail how you select firms in which to invest, and how this determines your earnings from the experiment.

\section{Your task as an investor}

During today's session, you will participate in several rounds of an activity in which you will be paired with different investors. In each round, the computer will randomly pair you with another investor. You will not know with which other investor you are paired in any round. You will also not know the outcomes of any rounds until the end of the experiment. 
In each round, the computer will also pair you and the other investor with two competing firms. Each firm corresponds to one of the CEOs who participated in a previous session of the experiment. In each round, you will see two new competing firms, and you will never see the same firm more than once.

The main task for you as an investor is to choose one of the competing firms in each round in which to invest. You earn money if both you and the other investor with whom you are paired in that round choose to invest in the same firm, otherwise you earn nothing. The game between you and the other investor can thus be described by the following table:

The other investor selects ...

Firm A

Firm A

You select. . .

\section{Firm $B$}

Firm $B$

\begin{tabular}{|c|c|}
\hline $\begin{array}{c}\text { Both investors earn } \\
\text { the same amount of } \\
\text { money }\end{array}$ & $\begin{array}{c}\text { Both investors earn } \\
\text { nothing }\end{array}$ \\
\hline $\begin{array}{c}\text { Both investors earn } \\
\text { nothing }\end{array}$ & $\begin{array}{c}\text { Both investors earn } \\
\text { the same amount of } \\
\text { money }\end{array}$ \\
\hline
\end{tabular}

In each round of the study, you and the other investor each choose one of the two firms independently and simultaneously. This means that when you decide in which firm to invest, you do not observe the choice that the other investor is making at the same time. You will have up to 60 seconds to decide in each round.

On the decision screen, you and the other investor will see the two firms presented in a random order. For instance, in the above example, the computer will randomly select whether you see "Firm A" on the left side of the screen and "Firm B" on the right side or vice versa. The computer will also randomly select each firm's position on the screen for the other investor, independently of what is selected for you. That is, what you see presented as "Firm A" may appear as "Firm B" for the other investor. Therefore, using the position of the firm on your screen or whether it appears first or second on your screen will not help you in matching the choice of the other investor.

You earn money only when both you and the other investor select the same firm. If you select different firms you earn nothing. Both you and the other investor will receive the same earnings in a round. The exact amount that you and the other investor can earn if you both select the same firm will depend on whether the products selected by that firm's CEO are successful. We describe below how these payoffs are determined. 


\section{The role of CEOs}

Today's session consists only of investors. CEOs have already participated in previous sessions.

The main task of the CEOs in this study is to attract investors to the CEO's firm. Specifically, in previous sessions, each CEO was asked to write a message to the investors. As an investor, you will read the messages from the CEOs of the two competing firms before deciding in which firm to invest. The message is therefore a possibility for each CEO to motivate why the investors should choose that CEO's firm.

At the end of their session, CEO's were also asked to make product choices. This will be explained in more detail below.

\section{Messages from CEOs}

When you see two competing firms in a round, you will also see a message written by each CEO attempting to convince you to invest in that CEOs firm. The messages of the competing firms will be displayed as in the following example:

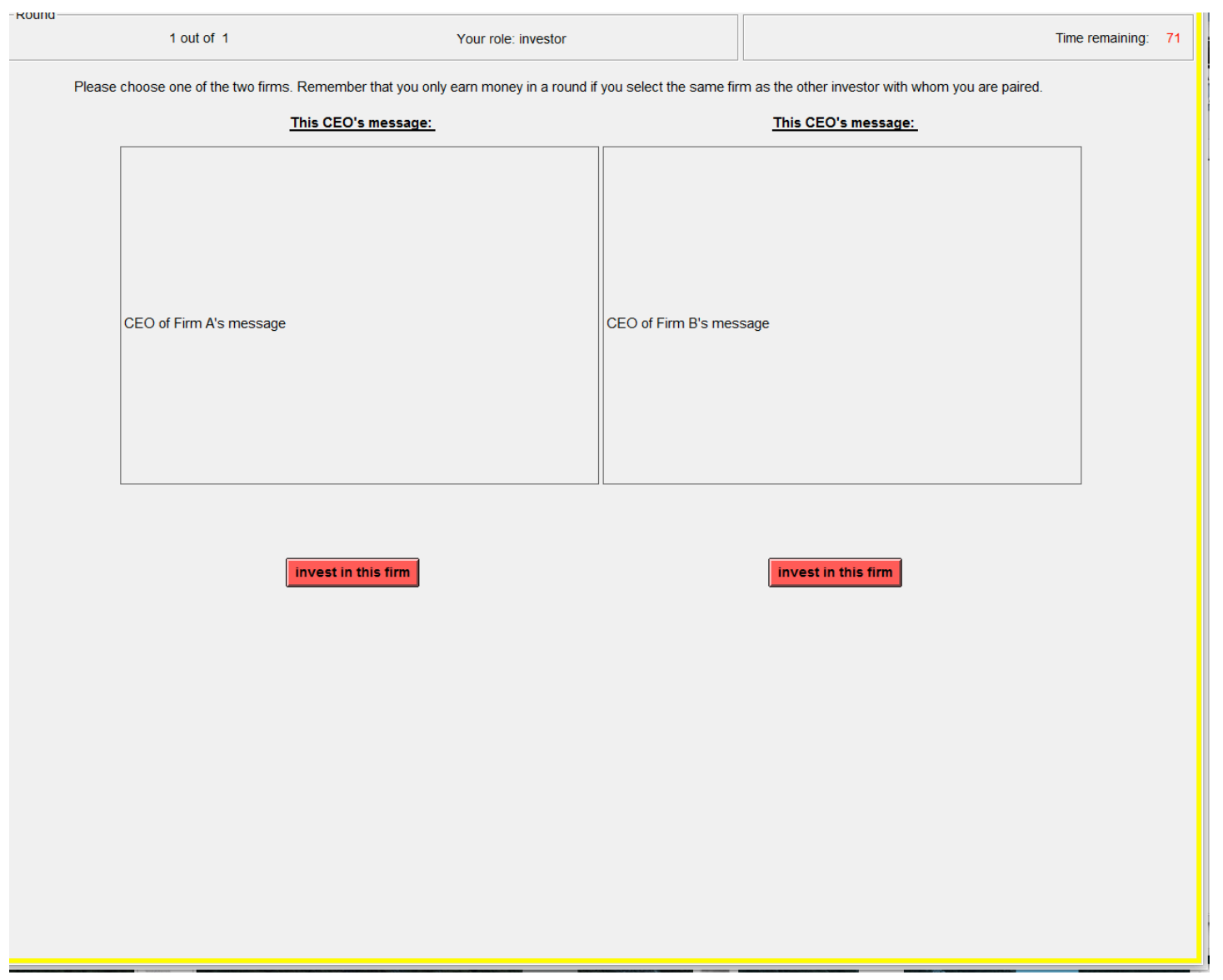


You will select one of the two firms by clicking the button below the message of the corresponding CEO. The order in which the CEOs messages appear will be random for you and for the other investor, meaning that the message one investor sees on the left side of the screen may appear either at the left or the right side of the other investor's screen. That is, you do not know whether the other investor also sees the two messages in the same order, or in the opposite order.

In some rounds, you will also see the portraits of the two CEOs along with the CEOs' messages. These portraits were taken during the previous sessions in which CEOs participated. The computer randomly determines whether or not the portraits are shown to the investors in a round. If the portraits are shown, they are always presented together, and always to both investors. That is, if you see the portraits in a round, then it is the portraits of the CEOs who wrote the specific messages that you see in that round, and the other investor with who you are paired in that round also sees the same portraits. The message from a particular CEO will be the same, regardless of whether or not that CEO's portrait is shown in a round.

\section{Selecting products}

CEOs have also selected 3 out of 6 possible products that their firm should develop and sell. To select products, the names of 6 products were shown on the CEOs' screens, and each CEO chose their preferred 3 products by clicking buttons next to each of these products. Note that CEOs made the product choices at the end of their session, after they had written their messages to investors.

After the sessions in which CEOs made their choices, the computer randomly drew 1 of the 6 products to be the successful product for this study. Each of the 6 products thus has an equal chance of being successful. As an investor, you earn more money by picking the same firm as the other investor, but you earn even more money by jointly picking a firm whose CEO selected a successful product. Note, however, that you will not know which CEOs selected successful products at the time you and the other investor make your choice in a round.

\section{Payoffs for investors}

Investors will receive a participation fee of CHF 15 for participating in the experiment. To determine your payoff from the interactions you have during today's session, the computer will randomly select one round. Your additional payoff will be based on the outcome of your decision, and the decisions of others, only in the randomly selected round. Since you will not know which round this will be, you should treat each round as if it could be the one that determines your earnings. 
Specifically, your payoffs in the selected round will be determined as follows:

- Investors each receive 0 CHF (in addition to the CHF 15 participation fee) if they do not both pick the same firm in the selected round.

- Investors each receive CHF 15 (in addition to the CHF 15 participation fee) if they pick the same firm and that firm's CEO does not select the successful product.

- Investors each receive CHF 25 (in addition to the CHF 15 participation fee) if they pick the same firm and that firm's CEO selects the successful product.

That means that by investing in the same firm, and selecting a firm with a successful product choice, you may generate a payoff of up to $25 \mathrm{CHF}$ in a round.

\section{Payoffs for CEOs}

Unlike investors, CEOs can earn money for every round in which their message is shown to investors. The message of each CEO will be used in at least 24 rounds. In each of these rounds, CEOs will be paired with a different competing firm, and with different investors. CEOs may earn money in each of these rounds, if they convince both investors to choose their firm.

The only thing that matters for the CEO's payoff in a round is whether or not both investors select the CEO's firm in that round. Specifically, the CEO's payoffs across all rounds will be determined as follows:

- If both investors select the CEO's firm in a round, the CEO will earn a payoff of 2 $\mathrm{CHF}$ for that round.

- Otherwise, the CEO will receive $0 \mathrm{CHF}$ for that round.

The final payoff for every CEO is the sum of these payments across all rounds of the study, plus the CHF 15 participation fee. CEOs will receive their additional payments once all of the sessions in this experiment are completed.

\section{Feedback}

No feedback about the outcomes of the investor's choices or the CEOs product choices will be given to participants until the end of the experiment, when participants receive their payment. That means that neither the CEOs, nor the investors, will know anything about the outcomes of specific rounds before their participation in the study is over.

\section{Start of the experiment}

Before you make any choices, we would like you to answer some control questions. These questions test whether you understand the procedures described in these instructions. The computer will guide you through the control questions. Once you have completed these questions, the first round of the study will start. In each round, you will choose one of the two competing firms. At the end of the study, you will complete a few short tasks and will then receive your participation fee. 
If you have any questions please raise your hand and wait for an experimenter to come to you.

Once everyone has completed the control questions, the study will begin. Please click the "Continue" button to start the control questions. 


\subsection{Experiment 2 - Instructions for Expert Prediction Task}

\section{Prediction task (Please write your name for payment:} )

Below is a description of an experiment conducted in Zurich, Switzerland, in September and October 2018. The experiment studies how players in a pure-matching coordination game respond to competing requests to play particular equilibria, when the requests come from men vs. women. Please read the description of the experimental task. Afterwards, please enter two guesses. For each guess, we will select the person whose guess is closest in absolute value to the actual percentage. Each of these people will receive 50 Euro.

\section{The experiment:}

Participants were recruited from the subject populations of the University of Zurich and the Swiss Federal Institute of Technology (ETH). The main experimental task consisted of two randomly-paired "Investors" playing a pure-matching coordination game. Each Investor chose between two "Firms" and their "CEOs" and received a payoff in a round only if both Investors selected the same firm. Specifically, the two investors received CHF 15 if they both chose the same Firm/CEO and CHF 0 otherwise. (Investors who coordinated could also receive an additional CHF 10 if the CEO they picked had correctly guessed a random number). Each Investor played a total of 24 rounds, in which they saw entirely different Firms/CEOs. Investors were paid for one randomly-selected round and received no feedback until the end of the experiment.

When making their decisions in a round, Investors observed a message from each firm's CEO stating why investors should select that CEO's firm. ${ }^{2}$ Specifically, Investors saw a screen like the one below on which they could read the messages written by the two CEOs and then make their choices. $^{3}$

\footnotetext{
${ }^{2}$ The CEOs participated in an earlier session in which each CEO had his/her portrait taken and had 40 minutes to write a statement recommending that investors select his/her firm. CEOs subsequently received CHF 2 for every one of the 24 rounds in which both investors selected that CEO's Firm.

${ }^{3}$ We randomized the presentation order of the two Firms within an Investor pair, so order could not be used to coordinate.
} 


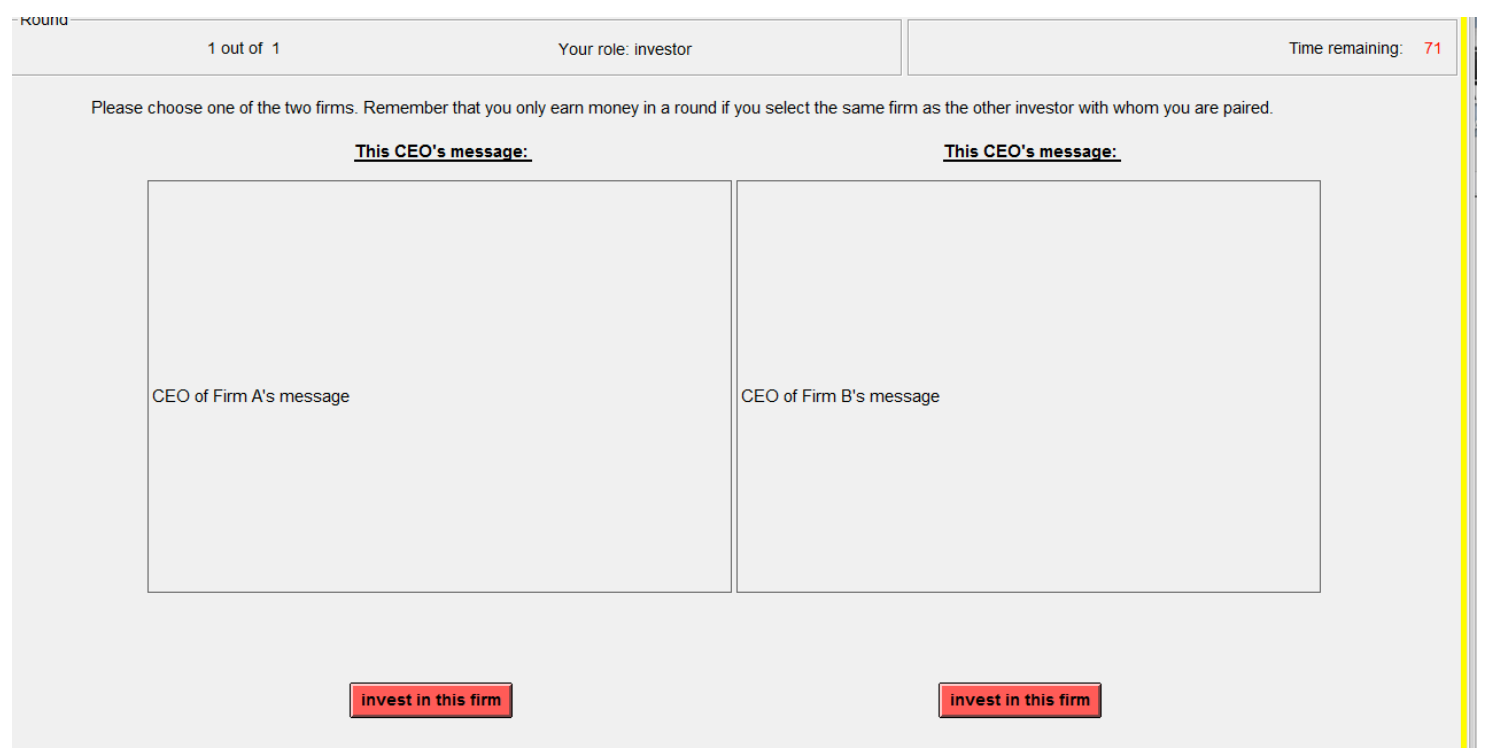

In one-half of the rounds, Investors also saw the portraits of the two CEOs, presented alongside the messages above. These portraits were taken by an experienced photographer against a neutral background.

Your guesses:

We are interested in cases in which one CEO was male and the other female. Specifically, in what percentage of such cases:

Did individual investors pick the male CEO when portraits were not visible? _ _ \%

Did individual investors pick the male CEO when portraits were visible? _ _ _ $\%$ 